\title{
RESEARCH
}

Open Access

\section{Sustained interleukin-10 delivery reduces inflammation and improves motor function after spinal cord injury}

Daniel J. Hellenbrand ${ }^{1,2}$, Kaitlyn A. Reichl ${ }^{1,2}$, Benjamin J. Travis ${ }^{1}$, Mallory E. Filipp ${ }^{1}$, Andrew S. Khalil², Domenic J. Pulito', Ashley V. Gavigan', Elizabeth R. Maginot', Mitchell T. Arnold ${ }^{1}$, Alexander G. Adler ${ }^{1}$, William L. Murphy ${ }^{2,3}$ and Amgad S. Hanna ${ }^{1 *}$

\begin{abstract}
Background: The anti-inflammatory cytokine interleukin-10 (IL-10) has been explored previously as a treatment method for spinal cord injury (SCl) due to its ability to attenuate pro-inflammatory cytokines and reduce apoptosis. Primary limitations when using systemic injections of IL-10 are that it is rapidly cleared from the injury site and that it does not cross the blood-spinal cord barrier.

Objective: Here, mineral-coated microparticles (MCMs) were used to obtain a local sustained delivery of IL-10 directly into the injury site after SCl.

Methods: Female Sprague-Dawley rats were contused at T10 and treated with either an intraperitoneal injection of IL-10, an intramedullary injection of IL-10, or MCMs bound with IL-10 (MCMs+IL-10). After treatment, cytokine levels were measured in the spinal cord, functional testing and electrophysiology were performed, axon tracers were injected into the brainstem and motor cortex, macrophage levels were counted using flow cytometry and immunohistochemistry, and lesion size was measured.
\end{abstract}

Results: When treated with MCMs+IL-10, IL-10 was significantly elevated in the injury site and inflammatory cytokines were significantly suppressed, prompting significantly less cells expressing antigens characteristic of inflammatory macrophages and significantly more cells expressing antigens characteristic of earlier stage antiinflammatory macrophages. Significantly more axons were preserved within the rubrospinal and reticulospinal tracts through the injury site when treated with MCMs+IL-10; however, there was no significant difference in corticospinal tract axons preserved, regardless of treatment group. The rats treated with MCMs+IL-10 were the only group with a significantly higher functional score compared to injured controls 28 days post-contusion.

Conclusion: These data demonstrate that MCMs can effectively deliver biologically active IL-10 for an extended period of time altering macrophage phenotype and aiding in functional recovery after $\mathrm{SCl}$.

Keywords: Interleukin-10, Macrophages, Microglia, Spinal cord injury, Inflammation

\footnotetext{
* Correspondence: hanna@neurosurgery.wisc.edu

${ }^{1}$ Department of Neurological Surgery, University of Wisconsin, Madison, WI

53792, USA

Full list of author information is available at the end of the article
}

(c) The Author(s). 2019 Open Access This article is distributed under the terms of the Creative Commons Attribution 4.0 International License (http://creativecommons.org/licenses/by/4.0/), which permits unrestricted use, distribution, and reproduction in any medium, provided you give appropriate credit to the original author(s) and the source, provide a link to the Creative Commons license, and indicate if changes were made. The Creative Commons Public Domain Dedication waiver (http://creativecommons.org/publicdomain/zero/1.0/) applies to the data made available in this article, unless otherwise stated. 


\section{Introduction}

Activated macrophages are typically described as belonging to two general categories: classically activated M1 macrophages expressing a pro-inflammatory phenotype or alternatively activated M2 macrophages expressing an anti-inflammatory phenotype. However, it is important to note that the M1/M2 paradigm is used as an idealized guide for a dynamic and mixed spectrum of microglia/ macrophage activation observed in vivo and antigens from both phenotypes may be expressed, as dictated by the environment. After skin and muscle injuries, there is sequential activation of classically activated pro-inflammatory M1 macrophages and alternatively activated M2a, M2b, and M2c macrophages, which facilitates in transitioning through inflammatory, proliferative, and remodeling phases of repair. After spinal cord injury (SCI), this sequential activation does not occur and pro-inflammatory macrophages potentiate a prolonged inflammation phase similar to what is observed in chronic non-healing wounds [1-4]. Although prolonged inflammation is detrimental, the immune cells instigated by the production of pro-inflammatory cytokines aid in preventing infection by phagocytosing bacteria, viruses, and foreign bodies near the injury site [5]. This emphasizes the importance of the inflammatory process and that SCI treatment may involve adjusting the timeline of M1 macrophages rather than inhibiting them.

M2 macrophages function in wound healing by producing anti-inflammatory cytokines, such as Interleukin-10 (IL-10), and aiding in the conversion of M1 macrophages to the M2 phenotype [6, 7]. Many studies performed over the past few decades have revealed the positive effects of IL-10 treatment post-SCI [8]. IL-10 treatments have been shown to protect against secondary inflammation by downregulating pro-inflammatory cytokines $[6,9,10]$, provide trophic support and neuroprotection $[11,12]$, and improve functional recovery in rat models [13-15]. However, research in IL-10 treatments has identified key obstacles, such as the rapid clearing of IL-10 from the injury site [16] and its inability to cross the blood-spinal cord barrier [17].

We hypothesized a sustained release of IL-10 directly in the injury site would induce the conversion of pro-inflammatory macrophages to an anti-inflammatory phenotype that decreases apoptosis and encourages tissue repair, thus preserving axons through the injury site and improving hind limb function after SCI. Here, we used mineral-coated microparticles (MCMs) to obtain a sustained delivery of IL-10 directly in the injury site.

\section{Materials and methods}

\section{Experimental design and statistical analysis}

The surgical procedures were performed following the NIH Guide for the care and use of laboratory animals and in accordance with protocols approved by the University of Wisconsin-Madison Animal Use \& Care Committee. The experimental design followed the timeline presented in Fig. 1a, using female Sprague-Dawley rats with an approximate weight and age of 225-250 g and 2 months, respectively (Sprague Dawley; Envigo, Huntingdon, UK). All rats were housed 2 per cage at

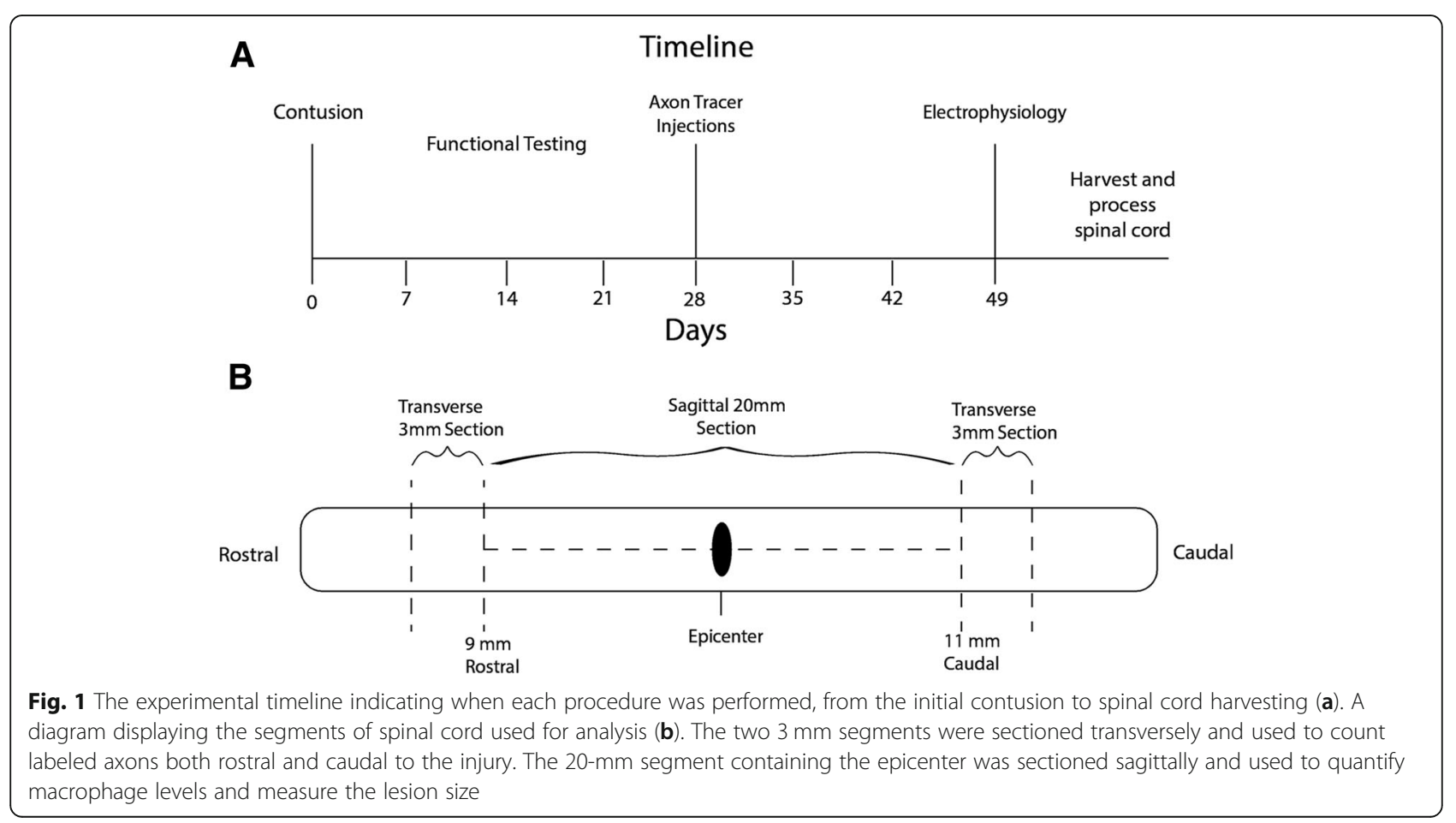


room temperature, standard light/dark cycle with food and water at lib.

The experiment utilized five test groups, to which rats were randomly assigned (Table 1). Prior to inclusion in the study, the rats were assessed using the Basso-Beattie-Bresnahan (BBB) locomotor scale to ensure there were no motor deficits. All groups underwent a spinal cord contusion injury at T10. The treatments compared were as follows: Control group, Systemic IL-10 group, Local IL-10 group, MCMs group, and MCMs+IL-10 group. Following the impaction, each group, excluding the Controls, received therapeutic intervention as described in Table 1. To determine group sizes, a power of analysis was conducted with $80 \%$ power and a significance level (alpha) of 0.05 (Student's $t$ test two-tailed, StatMate). For measuring the level of cytokines, a sample size of seven in each group at each test point $(24 \mathrm{~h}$ and 7 days) has $80 \%$ power to detect a difference between means of $20 \%$ and for functional testing a sample size of 10 in each group has $80 \%$ power to detect a difference between mean BBB scores of two.

All statistical analyses were performed in Prism 6 (GraphPad Software, San Diego, CA). Functional scores were analyzed using two-way ANOVA with days as the repeated measures; one-way ANOVA was used to analyze cytokine levels, axon counting, electrophysiology, macrophage levels, and lesion size. If results were deemed significant, Tukey's post-hoc analysis was used to test between groups or Dunnett's post-hoc analysis was used to compare treatments to Controls. Differences were considered significant at $P<0.05$. Quantitative data are presented as mean \pm standard error of the mean (SEM).

\section{Development of mineral-coated microparticles and IL-10 binding}

$\beta$-tricalcium phosphate $(\beta$-TCP) microparticles were obtained from Berkeley Advanced Biomaterials Inc. (Berkeley, CA). In order to form a calcium phosphate

Table 1 Descriptions of treatments tested including timing, dosage, and location

\begin{tabular}{|c|c|}
\hline Groups & Treatments \\
\hline Control & T10 contusion, no treatment \\
\hline $\begin{array}{l}\text { Systemic } \\
\text { IL-10 }\end{array}$ & $\begin{array}{l}50 \mu \mathrm{l} I \mathrm{~L}-10 \text { (concentration } 5 \mu \mathrm{g} I \mathrm{~L}-10 / 50 \mu \mathrm{l} 1 \mathrm{X} \text { PBS) } \\
\text { via IP injection } 30 \text { min post-impaction }\end{array}$ \\
\hline $\begin{array}{l}\text { Local IL- } \\
10\end{array}$ & $\begin{array}{l}5 \mu \mathrm{IL}-10 \text { (concentration } 10 \mu \mathrm{g} / 1 \mathrm{ml} 1 \mathrm{X} \text { PBS) } \\
\text { injected into the epicenter, } 1 \mu \mathrm{L} \text { at a time } \\
\text { in } 30-\mathrm{s} \text { intervals }\end{array}$ \\
\hline MCMs & $\begin{array}{l}5 \mu \mathrm{l} \text { MCMs (concentration } 20 \mathrm{mg} \mathrm{MCMs} / 1 \mathrm{ml} 1 \mathrm{XPBS} \text { ) injected } \\
\text { into the epicenter, } 1 \mu \mathrm{L} \text { at a time in } 30-\mathrm{s} \text { intervals }\end{array}$ \\
\hline $\begin{array}{l}\text { MCMs } \\
+\mathrm{IL}-10\end{array}$ & $\begin{array}{l}5 \mu \mathrm{l} \text { MCMs bound with IL-10 (concentration } 20 \mathrm{mg} \\
\text { of IL-10 MCMs/1 ml } 1 \text { X PBS) injected into the } \\
\text { epicenter, } 1 \mu \mathrm{L} \text { at a time in } 30 \text {-s intervals }\end{array}$ \\
\hline
\end{tabular}

Contused rats refers to all groups: Controls, Systemic IL-10, Local IL-10, MCMs, and MCMs+IL-10 mineral coating, the $\beta$-TCP microparticles were incubated for 7 days in modified simulated body fluid $(\mathrm{mSBF})$ at $37^{\circ} \mathrm{C}$ as previously reported [18-21]. The $\mathrm{mSBF}$ has similar ionic strength as human blood plasma with double the concentration of calcium and phosphate. The $\mathrm{mSBF}$ was prepared by adding the following reagents into deionized water in the order shown: 141 $\mathrm{mM} \mathrm{NaCl}, \quad 4.0 \mathrm{mM} \mathrm{KCl}, \quad 0.5 \mathrm{mM} \quad \mathrm{MgSO} 4, \quad 1.0 \mathrm{mM}$ $\mathrm{MgCl}_{2}, 4.2 \mathrm{mM} \mathrm{NaHCO}_{3}, 20.0 \mathrm{mM}$ HEPES, $5.0 \mathrm{mM}$ $\mathrm{CaCl}_{2}$, and $2.0 \mathrm{mM} \mathrm{KH}_{2} \mathrm{PO}_{4}$, and the $\mathrm{pH}$ was adjusted to 6.80 (Sigma, St. Louis, MO). After incubation in mSBF, the microparticles were strained through a $40-\mu \mathrm{m}$ screen and the morphology and composition of the calcium phosphate mineral coating on the microparticles were examined, after sputter coating with gold, by scanning electron microscopy and energy dispersive spectroscopy (EDS; LEO 1530 field emission scanning microscope; Zeiss, Oberkochen, Germany).

For IL-10 binding, 10-mg MCMs were incubated in $500 \mu \mathrm{L}$ of $1 \mathrm{X}$ PBS containing $2 \mu \mathrm{g}$ Recombinant Rat IL-10 (Peprotech, Rocky Hill, NJ, Cat\# 400-19) for 4 hours at $37{ }^{\circ} \mathrm{C}$. An in vitro test to determine efficacy of the sustained release of IL-10 from the MCMs was performed by incubating the MCMs with IL-10 bound in simulated body fluid at physiological conditions. The MCMs were switched to a new tube every other day and the amount of IL-10 released into solution was measured using an enzyme-linked immuno-sorbent assay kit (ELISA; Abcam Cambridge, UK; Cat\# ab100765).

\section{Spinal cord injury}

A laminectomy was completed at T10 exposing the spinal cord, and the rat was stabilized and slightly elevated off the platform by clamps on the T9 and T11 processes, after which a MASCIS Weight Drop machine (WM Keck Center for Collaborative Neuroscience, Rutgers University, Piscataway, NJ; Model II) was used to perform a 10-g weight drop from a height of $12.5 \mathrm{~mm}$. Immediately after impaction, the injections into the epicenter of the injury were completed at a depth of 1.5 $\mathrm{mm}$ at a rate of $1 \mu \mathrm{l}$ every $30 \mathrm{~s}$. The anesthetic agent used during this procedure was 16:1 ketamine/xylazine mixture via intraperitoneal injection.

Immediately following the completion of the SCI procedure, the rats received subcutaneous injections of 0.05 $\mathrm{mg} / \mathrm{kg}$ buprenorphine and $10 \mathrm{mg} / \mathrm{kg}$ enrofloxacin to control pain and prevent infections, respectively. They also received an antibiotic-enriched diet, Uniprim (Envigo, Huntingdon, United Kingdom; Cat\# TD.06596), for 1 week following SCI. The rats' bladders were expressed twice daily until function was regained. Animals with urinary tract infections were treated for 5 days with $10 \mathrm{mg} / \mathrm{kg}$ enrofloxacin once a day, subcutaneously. The efficacy of the SCI was determined on day one 
post-operation through $\mathrm{BBB}$ functional testing; a day one baseline BBB score of three or higher indicated an atypical injury, prompting immediate exclusion from the study.

\section{Cytokine levels in the spinal cord}

Cytokine levels were measured at $24 \mathrm{~h}$ and 7 days after SCI. After the predetermined waiting period, the rats were given a lethal dose of isoflurane and their blood was flushed out with $0.9 \%$ saline transcardially. Immediately after flushing the blood, a 4-mm section of the spinal cord centered at the epicenter of the injury site was taken and weighed. The section of spinal cord was then minced using a scalpel and homogenized. The homogenates were placed in lysate buffer and centrifuged at $12,000 \times g$ for $15 \mathrm{~min}$ at $4{ }^{\circ} \mathrm{C}$. The supernatants were removed, aliquoted on ice, and placed in a $-80^{\circ} \mathrm{C}$ freezer. To quantify cytokine levels, ELISA kits for detecting IL-10, tumor necrosis factor-alpha (TNF $\alpha$ ), and interluekin-1 beta (IL-1 $\beta$ ) were used and performed according to manufacturer's directions (ELISA kit; Abcam Cambridge, UK; IL-10: Cat\# ab100765, TNF $\alpha$ : Cat\# ab100785, IL-1ß: Cat\# ab100768). The results for each group are presented as the percent increase from uninjured rats.

\section{Macrophage phenotype \\ Flow cytometry}

Seven days post-SCI, the rats were given a lethal dose of isoflurane and their blood was flushed out with $0.9 \%$ saline transcardially. Immediately after flushing the blood, a 4-mm section of the spinal cord centered at the epicenter of the injury site was harvested. The excised tissue was mechanically digested for 5 min using a scalpel prior to incubation in $1 \mathrm{~mL}$ of a fivefold dilution of $10 \times$ collagenase/hyaluronidase in DMEM (StemCell Technologies Cat\# 07912) for $30 \mathrm{~min}$ at $37^{\circ} \mathrm{C}$ on a rotary mixer to which 200 Units/mL of DNase I (Sigma-Aldrich Cat\# DN25-1G) was added. The enzymatic digest was titrated $20 \times$ with a $1-\mathrm{mL}$ micropipette and followed by addition of $1 \mathrm{~mL}$ of DMEM containing 10\% FBS. The cells were centrifuged at $500 \times g$ for $5 \mathrm{~min}$ and washed 2 times with PBS and strained through a $100-\mu \mathrm{m}$ cell strainer on the last wash. The cells were incubated in $1 \mu \mathrm{L} / \mathrm{mL}$ of Ghost Dye Red 780 live/dead (TonboBio Cat\# 13-0865-T100) for $30 \mathrm{~min}$ at $4{ }^{\circ} \mathrm{C}$ protected from light. PBS containing 10\% FBS was added to the live/ dead stain after $30 \mathrm{~min}$ and the cells were centrifuged at $500 \times g$ for 5 min following a second wash with PBS containing $10 \%$ FBS. The inclusion of $10 \%$ FBS was used to block non-specific binding sites [22-24]. The cells were resuspended in $1 \%$ formaldehyde in PBS and incubated for $20 \mathrm{~min}$ at room temperature protected from light. The fixed cells were centrifuged at $500 \times g$ for $5 \mathrm{~min}$ and washed once with PBS. The cells were then resuspended in ice cold $90 \%$ methanol in PBS for storage until labeling for flow cytometry.

Cells were labeled for all macrophages using CD11b and CD45. Ramified microglia are $\mathrm{CD} 11 \mathrm{~b}^{+} \mathrm{CD} 45^{\mathrm{LOW}}$ and fully activated macrophages are $\mathrm{CD} 11 \mathrm{~b}^{+} \mathrm{CD} 45^{\mathrm{HIGH}}$ $[25,26]$. M1-specific markers CD68 and CD80, M1 or M2b marker CD86, and M2c marker CD163 were used to further distinguish macrophage phenotype on the $\mathrm{CD}_{11} \mathrm{~b}^{+} \mathrm{CD} 45^{\mathrm{HIGH}}$ cell population $[1,27]$. Eight samples selected at random were pooled and counted using a hemocytometer to determine the average cell isolation yield. This yield average was used to estimate the cell isolation concentrations and approximately 250,000 cells were used for antibody labeling and subsequent flow cytometry analysis. The cells were added to a 96-well polypropylene v-bottom plate and washed 2 times with $0.5 \%$ BSA in PBS, referred to as flow bluffer 1 (FB1), to remove the $90 \%$ methanol storage solution. The cells were then incubated in $100 \mu \mathrm{L}$ of primary antibody solutions at 1:10 dilutions for CD11b-Pacific Blue (Bio-Rad/AbD Serotec Cat\# MCA275PB, RRID:AB_566459), CD163Biotin (Bio-Rad/AbD Serotec Cat\# MCA342B, RRID:AB_2074559), CD68-PE (Bio-Rad/AbD Serotec Cat\# MCA341PE, RRID:AB_324585), CD86-Alexafluor 647 (Bio-Rad/AbD Serotec Cat\# MCA2874A647, RRID:AB_1719961), and CD45-PE/Alexafluor 750 (Bio-Rad/ AbD Serotec Cat\# MCA43P750, RRID:AB_10673436) and 1:1 dilution for CD80-FITC (LS Bio Cat\#C188420100 ) in PBS containing 0.5\% FBS and $0.1 \%$ TritonX-100, referred to as flow buffer 2 (FB2), for $1 \mathrm{~h}$ at room temperature and protected from light. The primary-labeled cells were washed 2 times with FB2 and then incubated in $100 \mu \mathrm{L}$ of secondary antibody at 1:2000 dilution for Streptavidin-Alexafluor 430 (Thermo Fisher Scientific Catalog \#S11237) in FB2 (or just $100 \mu \mathrm{L}$ FB2 with no secondary for the primary-fluorophore conjugates) for $30 \mathrm{~min}$ at room temperature protected from light. The fully labeled cells were washed 2 times in FB2 and resuspended in FB1 for flow cytometry analysis. Aliquots from 8 samples were additionally pooled and labeled with the above protocol containing all primaries minus one for each antigen, referred to as fluorescence minus one (FMO). Each primary (and corresponding secondary if applicable) were also individually added to 1 drop of UltraComp eBeads (Thermo Fisher Scientific Catalog \#01-2222-41) at the cell labeling concentrations for fluorescence signal compensation. Each sample, compensation control, and FMO were run on an Attune Nxt (Thermo Fisher Scientific) and 10,000 single and live cell events were collected. After application of compensation to the sample data, a positive gate for each antigen was determined as sample fluorescence above $\sim 1 \%$ positive expression in the appropriate FMO for single livestained cells. 


\section{Macrophage labeling and quantification}

Seven weeks post injury, spinal cords were harvested and paraffin embedded. Sagittal segments were sectioned $10-\mu \mathrm{m}$ thick and placed on slides. Sections were deparaffinized and rehydrated. A 1:100 antigen unmasking solution in distilled water was used to expose antigens (Vector Laboratories Cat\# H-3300, RRID: AB_2336226). The slides were then washed with $0.1 \mathrm{M}$ PBS for $5 \mathrm{~min}$, followed by $1 \mathrm{~h}$ in $\mathrm{nDS}$ blocker ( $4 \% \mathrm{nDS}, 1 \% \mathrm{BSA}, 0.5 \%$ Triton, $0.1 \mathrm{M} \mathrm{PBS}$ ). The primary staining solution consisted of $10 \mu \mathrm{g} / \mathrm{mL}$ biotinylated tomato lectin (TL) (Vector Laboratories Cat\# B-1175, RRID: AB_2315475), 1:100 mouse-anti-CD163 (Bio-Rad/AbD Serotec Cat\# MCA342GA, RRID: AB_2074558), and 1:100 rabbit-anti-MARCO (macrophage receptor with collagenous structure) (Abcam Cat\# ab108113, RRID: AB_10861943) combined with 25\% blocker and 75\% 0.1 $\mathrm{M}$ PBS. The slides were submerged in the primary solution for $24 \mathrm{~h}$ at $4{ }^{\circ} \mathrm{C}$. The slides were then rinsed with $0.1 \mathrm{M}$ PBS. A secondary solution composed of Streptavidin 350 (Thermo Fisher Scientific Cat\# S11249), donkey-anti-mouse 594 (Thermo Fisher Scientific Cat\# A-21203, RRID: AB_2535789), and donkey-anti-rabbit 488 (Thermo Fisher Scientific Cat\# A-21206, RRID: AB_2535792) all in a 1:500 ratio with 0.1 M PBS was applied to the slides for $1 \mathrm{~h}$ at room temperature. The slides were again rinsed with $0.1 \mathrm{M}$ PBS and cover slipped with Prolong Gold without DAPI (Thermo Fisher Scientific Cat\# P36930).

Five rats from each group were analyzed. All sections were imaged with a Keyence BZ-9000 fluorescence microscope (Keyence, Osaka, Japan). To quantify macrophages, a $\times 20$ image of the injury site was taken in three sections from each rat and the percent of area stained was calculated in each image using Image $(\mathrm{NIH}, \mathrm{Be}-$ thesda, MD).

\section{Functional testing}

Functional recovery was assessed weekly for 4 weeks post-injury through visual observation using the $\mathrm{BBB}$ locomotor rating scale. During the assessment, the rats were continuously videotaped for a period of $4 \mathrm{~min}$ in an open field. The BBB scale, a functional analysis, was used to evaluate rats with SCI rating them from 0 to 21 based on a combination of limb and joint movement, limb coordination, stability, tail position, and abdomen position [28]. Individuals blinded to the treatment groups completed all scoring.

\section{Axon tracer injections and axon counting}

Four weeks after SCI, seven rats from each group underwent anterograde axon tracing with a $10 \%$ biotinylated dextran amine (BDA) (Thermo Fisher Scientific Cat\# D1956, RRID: AB_2307337) in saline, as previously reported [29]. Three of the seven rats received BDA injections in eight sites of the motor cortex (MC). The following coordinates were used to inject $1 \mu \mathrm{lBDA}$ per site at a rate of $0.2 \mu \mathrm{l}$ every $30 \mathrm{~s}$, using the bregma as the zero point: anterior-posterior (AP), $1 \mathrm{~mm}$; medial-lateral (ML), $\pm 1.8 \mathrm{~mm}$; dorsal-ventral (DV, from dural surface), $1.0 \mathrm{~mm}$; AP, $0 \mathrm{~mm}$; ML, $\pm 2 \mathrm{~mm}$; DV, $1 \mathrm{~mm}$; AP, $+1 \mathrm{~mm} ; \mathrm{ML}, \pm 2.2 \mathrm{~mm}$; DV, $1 \mathrm{~mm}$; AP, $+2 \mathrm{~mm}$; ML, \pm $2.6 \mathrm{~mm}$; DV, $1 \mathrm{~mm}$. The remaining four rats received BDA injections into the red nucleus (RN) and reticular formation (RF) of the brainstem, $0.5 \mu \mathrm{l} \mathrm{BDA}$ per site at a rate of $0.1 \mu \mathrm{l}$ every $30 \mathrm{~s}$. Using the bregma as the zero point, the following coordinates were used: $\mathrm{RN}$ : AP, 5.8 $\mathrm{mm}$; ML, $\pm 1.2 \mathrm{~mm}$; DV, $7 \mathrm{~mm}$; RF: AP, $11.6 \mathrm{~mm}$; ML, \pm $1 \mathrm{~mm}$; DV, $6 \mathrm{~mm}$. For both the brainstem and MC injections, the needle remained in place for $1 \mathrm{~min}$ post-injection to allow for tissue absorption. The anesthetic agent used for this procedure was $4 \%$ isoflurane in oxygen to anesthetize the rats and maintained for the duration of the surgery at $2-3 \%$ isoflurane in oxygen. The MC and brainstem-injected rats were maintained alive for an additional 2 and 3 weeks, respectively, post-injection. They then received a lethal dose of isoflurane, were perfused with $0.9 \%$ saline followed by $4 \%$ paraformaldehyde (PFA; Sigma; Cat\# 441244) in $0.1 \mathrm{M}$ PBS, pH 7.4, transcardially, and the spinal cords were harvested.

The harvested cords were submerged in 4\% PFA for $24 \mathrm{~h}$ and then parsed into three sections: two 3- $\mathrm{mm} \mathrm{sec}-$ tions taken 11-mm caudal and 9-mm rostral to the epicenter of the injury site, and the remaining 20-mm section containing the injury site (Fig. 1b). The two 3-mm sections were placed into a 30\% sucrose solution (Sucrose, Sigma, Cat\# S7903) for $48 \mathrm{~h}$, frozen in Tissue-Tek ${ }^{\bullet}$ and sectioned transversely at a thickness of $20 \mu \mathrm{m}$. The $20 \mathrm{~mm}$ section containing the epicenter was cut sagittally along the ventral split, dehydrated in alcohol, embedded in paraffin, and sectioned $10-\mu \mathrm{m}$ thick for macrophage counting and lesion size analysis.

Slides containing transverse sections of spinal cord from rostral and caudal to the injury site, as shown in Fig. $1 \mathrm{~b}$, were rinsed with $0.1 \mathrm{M}$ PBS for $10 \mathrm{~min}$, followed by 1 hour in normal donkey serum (nDS) blocker $(4 \%$ nDS, $1 \%$ bovine serum albumin (BSA), $0.5 \%$ Triton, 0.1 $\mathrm{M}$ PBS). The slides were then submerged in the secondary solution consisting of a 1:500 ratio of Streptavidin 594 (Thermo Fisher Scientific Cat\# S-11227, RRID: AB_2313574) to $0.1 \mathrm{M}$ PBS for 2 hours in the dark at room temperature. Then, the slides were rinsed with 0.1 M PBS and cover slipped using Prolong Gold with 4',6-diamidino-2-phenylindole (DAPI) (Thermo Fisher Scientific Cat\# P36930).

Three $20-\mu \mathrm{m}$ transverse sections from each the rostral 3-mm segment and the caudal 3-mm segment were 
used. The average of the three rostral sections was considered the total number of axons labeled in each rat, with the average of the three caudal sections representing the number of labeled axons crossing the injury site. All sections were imaged on a Keyence BZ-9000 fluorescence microscope (Keyence, Osaka, Japan). Using the Keyence Analyzer software, a region of interest was drawn excluding the gray matter and the numbers of axons with a size between 1 and $15 \mu \mathrm{m}$ in diameter were quantified.

\section{Electrophysiology}

Rats were anesthetized with $16: 1$ ketamine/xylazine mixture via intraperitoneal injection. Three rats from each group underwent electrophysiology testing to measure the cord dorsum potential (CDP). The spinal cord was exposed by means of a laminectomy at the T8 and T11 levels. Clamps were placed on the spinous processes of T7 and T12 to stabilize and elevate the rat. Upon opening the dura at T8, the cathode stimulating monopolar microelectrode (Microprobes for Life Sciences, Gaithersburg, MD, Cat\# PI20030.5A10) was placed at a depth of $0.9 \mathrm{~mm}$ below the dural surface, and the recording hook electrode (NeuroSign, The Magstim Company Limited, Wales, UK, Cat\# 4009-00) rested gently on top of the intact dura at the T11 level, approximately $15-\mathrm{mm}$ caudal to the stimulating electrode (Fig. 11a). The anode needle for stimulation was placed in the muscle directly adjacent to the microelectrode.

A constant current stimulus isolator (World Precicion Instruments Model A385) was used to send a 400- $\mu \mathrm{A}$ current for a duration of $25 \mu \mathrm{s}$, the signal was amplified (Grass Model 7P511) and the average of 30 pulses was read into LabView. The conduction velocity was calculated from the distance between the stimulating and recording electrode divided by the time between the stimulus and the CDP. The amplitude was measured from peak-to-peak.

\section{Lesion size analysis}

The lesion size was determined using the sagittal 20-mm paraffin embedded spinal cord segments (Fig. 1b), which were sectioned $10-\mu \mathrm{m}$ thick. Sections were deparaffinized and rehydrated. A 1:100 antigen unmasking solution in distilled water was used to expose antigens (Vector Laboratories Cat\# H-3300, RRID: AB_2336226). The slides were then washed with $0.1 \mathrm{M} \mathrm{PBS}$, followed by $1 \mathrm{~h}$ in $\mathrm{nDS}$ blocker (4\% nDS, 1\% BSA, $0.5 \%$ Triton, $0.1 \mathrm{M}$ PBS). The slides were submerged in the primary solution, consisting of a 1:1000 ratio of rabbit-anti-glial fibrillary acidic protein (GFAP; Abcam Cat\# ab7260, RRID: AB_305808) combined with 25\% blocker and 75\% $0.1 \mathrm{M}$ PBS, for $24 \mathrm{~h}$ at $4{ }^{\circ} \mathrm{C}$. The slides were then rinsed with $0.1 \mathrm{M}$ PBS. The secondary solution consisting of 1:500 of donkey-anti-rabbit 488 (Thermo Fisher
Scientific Cat\# A-21206, RRID: AB_2535792) in 0.1 M PBS was applied to the slides for $1 \mathrm{~h}$ at room temperature. The slides were again rinsed with $0.1 \mathrm{M}$ PBS and cover slipped with Prolong Gold containing DAPI (Thermo Fisher Scientific Cat\# P36930).

Four sections were analyzed per rat, with four rats from each group. In order to properly assess lesion size, two metrics were considered: the amount of spinal atrophy and the size of the infarct. The sectioned tissue was imaged on a Keyence BZ-9000 fluorescence microscope, and quantified using Image software (NIH, Bethesda, Maryland). To determine the level of spinal atrophy present, the diameter of the cord at the epicenter as well as $5-\mathrm{mm}$ rostral and $5-\mathrm{mm}$ caudal to the epicenter were measured. The rostral and caudal measurements were averaged and the epicenter measure was subtracted from the average. To determine the size of infarct, the area of necrotic tissue was measured.

\section{Results \\ MCMs and IL-10 delivery in vitro}

Following a 7-day incubation in $\mathrm{mSBF}$, scanning electron microscopy revealed an uninterrupted nanoporous plate-like mineral coating covering the entire surface of the MCMs (Fig. 2a, b). Over a course of 17 days, an in vitro release profile of IL-10 from the MCMs was quantified using an ELISA kit. The profile expressed an initial burst release of $5.18 \pm 0.5 \mathrm{ng}$ of IL-10 per milligram of MCMs on day one, followed by a linear continuous release for at least 17 days. On day 17 the MCMs with IL-10 bound released $981 \pm 270$ pg of IL-10 per milligram of MCMs, with a cumulative release of $20.15 \mathrm{ng}$ of IL-10 per milligram of MCMs over the entire 17 day period (Fig. 2c).

\section{Cytokine levels \\ IL-10}

At $24 \mathrm{~h}$ post-SCI, there was a significant difference in IL-10 expression between the groups $\left(\mathrm{F}_{4,30}=3.972, P=0.015\right.$, ANOVA; Fig. 3a). MCMs+IL-10 had a $111.6 \pm 16.63 \%$ increase in IL-10 as compared to uninjured rats. This was significantly higher than the Controls at $45.5 \pm 8.83 \%$ $(P=0.0235)$, Local IL-10 at $49.14 \pm 19.14 \%(P=0.0359)$, and MCMs at $49.20 \pm 12.57 \%(P=0.0361)$, all as the percent increase from uninjured rats. Systemic IL-10 was $82.99 \pm 13.18 \%$, which was not significantly different than the MCMs+IL-10 treatment $(P=0.6349)$.

Seven days post-SCI, there was also a significant difference between groups $\left(F_{4}, \quad 30=4.527, \quad P=0.0056\right.$, ANOVA; Fig. 3b). MCMs+IL-10 had an even higher percent increase of IL-10, with $184.7 \pm 18.70 \%$ increase from uninjured rats. MCMs+IL-10 still had significantly higher IL-10 than the Controls at $102.4 \pm 16.08 \%(P=0.0124)$, Local IL-10 at $99.74 \pm 16.35 \%(P=0.0094)$, and MCMs at 

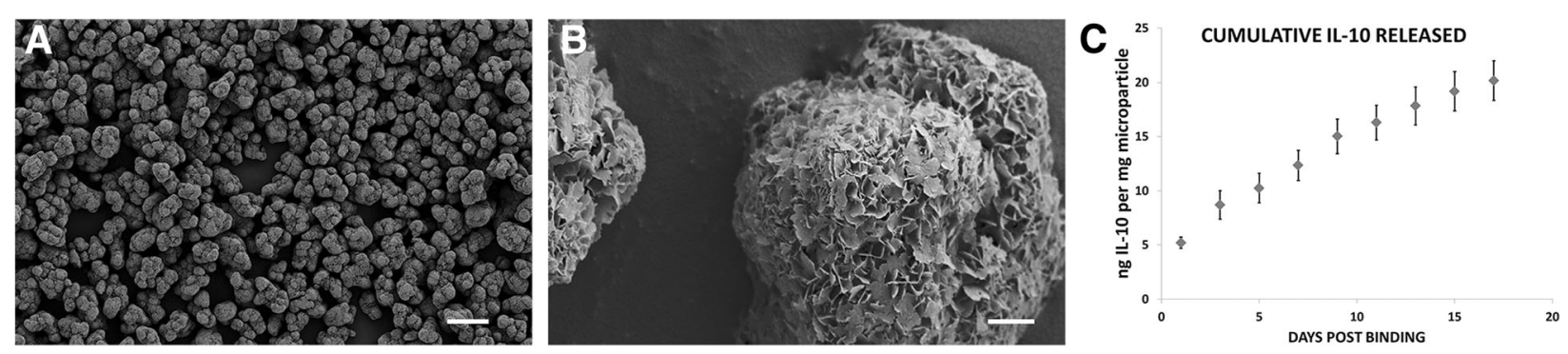

Fig. 2 Mineral coated $\beta$-TCP microparticles and IL-10 delivery in vitro. After incubation in mSBF, scanning electron microscopy images reveal a continuous plate-like mineral coating covering the entirety of the MCMs $(\mathbf{a}, \mathbf{b})$, allowing for sufficient binding of IL-10. At physiological conditions in SBF, the release profile of IL-10 from the MCMs was quantified using an ELISA kit. There was an initial burst release of IL-10, followed by a continuous release for at least 17 days (c). Scale bars equal $40 \mu \mathrm{m}$ in $\mathbf{a}, 1 \mu \mathrm{m}$ in $\mathbf{b}$; error bars represent \pm SEM in $\mathbf{c}$

$106.2 \pm 21.44 \%(P=0.0185)$, as percent increases from uninjured rats. Systemic IL-10 at a $125.1 \pm 7.81 \%$ increase from uninjured rats was not significantly different than MCMs+IL-10 $(P=0.1128)$.

\section{TNFa}

At $24 \mathrm{~h}$ post-SCI, there was a significant difference in TNF $\alpha$ levels between groups $\left(F_{4}, 30=10.21, P=0.0001\right.$, ANOVA; Fig. 3c). MCMs+IL-10 and Systemic IL-10 had the lowest TNF $\alpha$ percent increases, at $71.43 \pm 13.88 \%$ and $73.57 \pm 14.90 \%$, respectively, as percent increases from uninjured rats. There was no significant difference between MCMs+IL-10 and Systemic IL-10 ( $P=0.9999)$. MCMs+IL-10 and Systemic IL-10 had significantly less TNF $\alpha$ than the Controls at $200.4 \pm 12.77 \%\left(P_{\text {MCMs }+ \text { IL-10 }}\right.$ $\left.=0.0027, P_{\text {SystemicIL-10 }}=0.0033\right)$, Local IL-10 at $185.5 \pm$ $18.60 \% \quad\left(P_{\text {MCMs }+ \text { IL-10 }}=0.0093, \quad P_{\text {Systemicll-10 }}=0.0110\right)$, and MCMs at $218.6 \pm 39.86 \%\left(P_{\mathrm{MCMs}}+\mathrm{IL}-10=0.0006, P_{\mathrm{Sy}-}\right.$ stemicIL-10 $=0.0007$ ), all shown as percent increases from uninjured rats.

At seven days post-SCI, there was also a significant difference between groups in TNF $\alpha$ levels $\left(F_{4,30}=9.810\right.$, $P<0.0001$, ANOVA; Fig. 3d). MCMs+IL-10 still had significantly lower TNFa concentrations than the Controls at $211.7 \pm 16.09 \%(P=0.0002)$, Local IL-10 at $201.1 \pm 10.47 \% \quad(P=0.0006)$, and MCMs at 224.1 \pm 44.43\% $(P=0.0001)$ but Systemic IL-10 did not, as it increased to $139.3 \pm 14.66 \%\left(P_{\text {Controls }}=0.2013, P_{\text {LocallL-10 }}\right.$ $=0.3435$, and $\left.P_{\text {MCMs }}=0.0967\right)$, with all results depicted as the percent increase from uninjured rats. Despite this difference, Systemic IL-10 and MCMs+IL-10 did not have significantly different TNF $\alpha$ concentrations $(P=0.0707)$.

\section{IL-1 $\beta$}

At $24 \mathrm{~h}$ post-SCI, there was a significant difference between groups $\left(F_{4}, 30=15.44, P=0.0001\right.$, ANOVA; Fig. 3e). Similar to TNF $\alpha$ at $24 \mathrm{~h}$ post-SCI, MCMs + IL-10 and Systemic IL-10 had significantly less IL-1 $\beta$ than the Controls at $96.6 \pm 4.99 \% \quad\left(P_{\mathrm{MCMs}+\mathrm{IL}-10}=\right.$ $\left.0.0003, P_{\text {SystemicIL-10 }}=0.0084\right)$, Local IL-10 at $86.52 \pm$
$19.01 \% \quad\left(P_{\text {MCMs }+ \text { IL-10 }}=0.0017, \quad P_{\text {SystemicIL-10 }}=0.0362\right)$, and MCMs at $130.6 \pm 11.34 \%\left(P_{\mathrm{MCMs}}+\mathrm{IL}-10<0.0001\right.$, $\left.P_{\text {SystemicIL-10 }}<0.0001\right)$, with all results depicted as the percent increase from uninjured rats. MCMs+IL-10 and Systemic IL-10 did not vary significantly with expression at $14.32 \pm 5.273 \%$ and $34.67 \pm 13.54 \%$, respectively, as percent increases from uninjured rats $(P=0.7547)$. At 7 days post-SCI, there were no significant differences of IL-1 $\beta$ between groups $\left(F_{4,30}=2.366\right.$, $P=0.0752$, ANOVA; Fig. 3f).

\section{Macrophage phenotype Flow cytometry}

Seven days after injury, spinal cords were minced, cells were disassociated then stained with antibodies to recognize all macrophages (CD45 and CD11b), M1-specific macrophages (CD68 and CD80), M1 or M2b macrophages (CD86), and $\mathrm{M} 2 \mathrm{c}$ macrophages (CD163). There was no significant difference in the number of $\mathrm{CD}_{11 \mathrm{~b}^{+}} \mathrm{CD} 45^{\mathrm{HIGH}}$ cells between groups $\left(\mathrm{F}_{4,14}=2.392\right.$, $P=0.1003$, ANOVA; Fig. 4).

The expression of CD68 was significantly different between groups $\left(\mathrm{F}_{4,14}=4.624, P=0.0137\right.$, ANOVA; Fig. 5 Column 1). MCMs+IL-10 had significantly less CD68 expression as compared to Controls $(P=0.0121)$, while no other group had a significant difference as compared to Controls $\left(P_{\text {Systemic IL-10 }}=0.0960, P_{\text {Local IL-10 }}=0.9918\right.$, $\left.P_{\text {MCMs }}=0.6003\right)$. There was no difference observed in expression of CD80 $\left(\mathrm{F}_{4,14}=1.822, P=0.1806\right.$, ANOVA; Fig. 5 Column 2), CD86 $\left(\mathrm{F}_{4}, 14=0.5947, P=0.6723\right.$, ANOVA; Fig. 5 Column 3), or CD163 $\left(\mathrm{F}_{4,14}=1.215\right.$, $P=0.3481$, ANOVA; Fig. 5 Column 4). All CD11b ${ }^{+}$ $\mathrm{CD} 45^{\mathrm{HIGH}}$ cells were futher analyzed for macrophage phenotype.

For distinction throughout this paper, macrophages $\left(\mathrm{CD} 11 \mathrm{~b}^{+} \mathrm{CD} 45^{\mathrm{HIGH}}\right)$ that were $\mathrm{CD}^{+} 8^{+}$or $\mathrm{CD}^{+} 0^{+}$were considered "M1," those that were $\mathrm{CD} 68^{-} \mathrm{CD} 80^{-} \mathrm{CD} 86^{+} \mathrm{CD} 163^{-}$ were considered "M2b," and those that were $\mathrm{CD}^{-} 8^{-} \mathrm{CD} 80^{-} \mathrm{CD}^{-} 6^{-} \mathrm{CD} 163^{+}$were considered "M2c." CD86 is expressed on both M1 and M2b macrophages; however, 

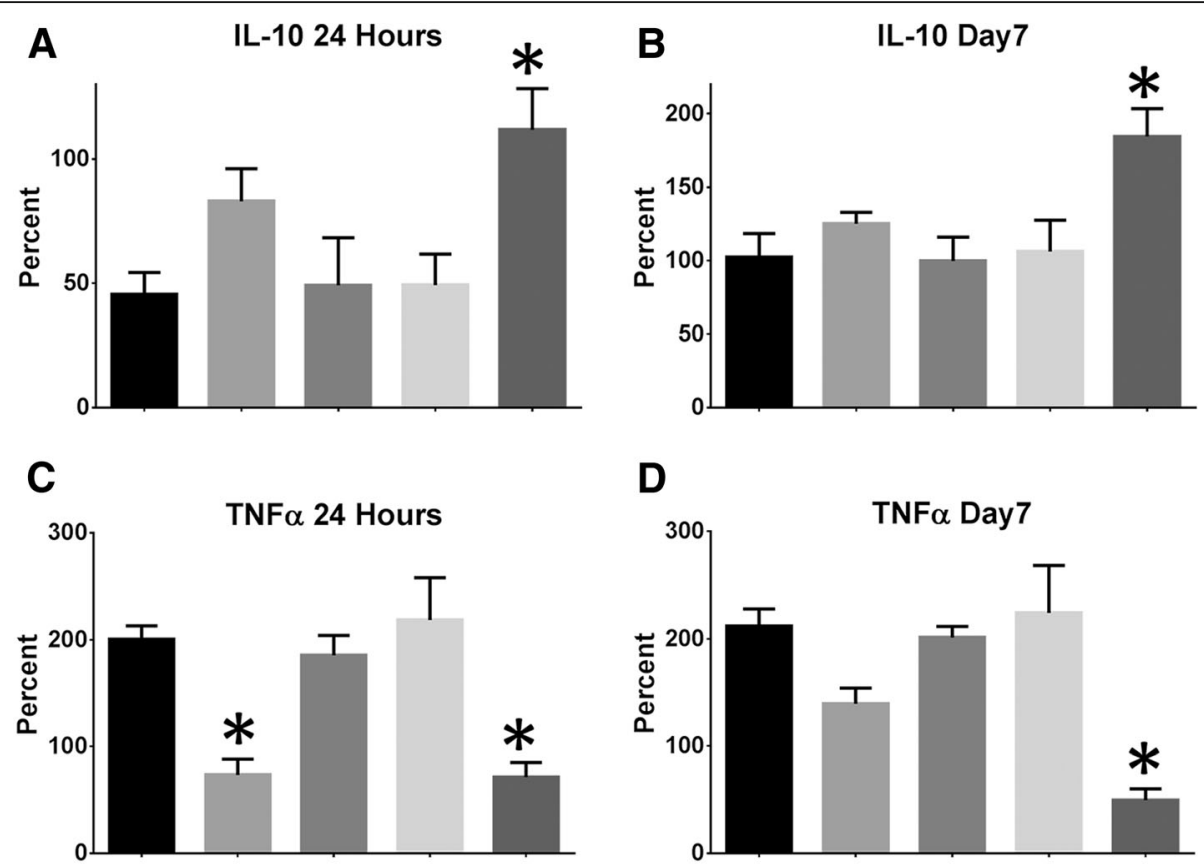

D
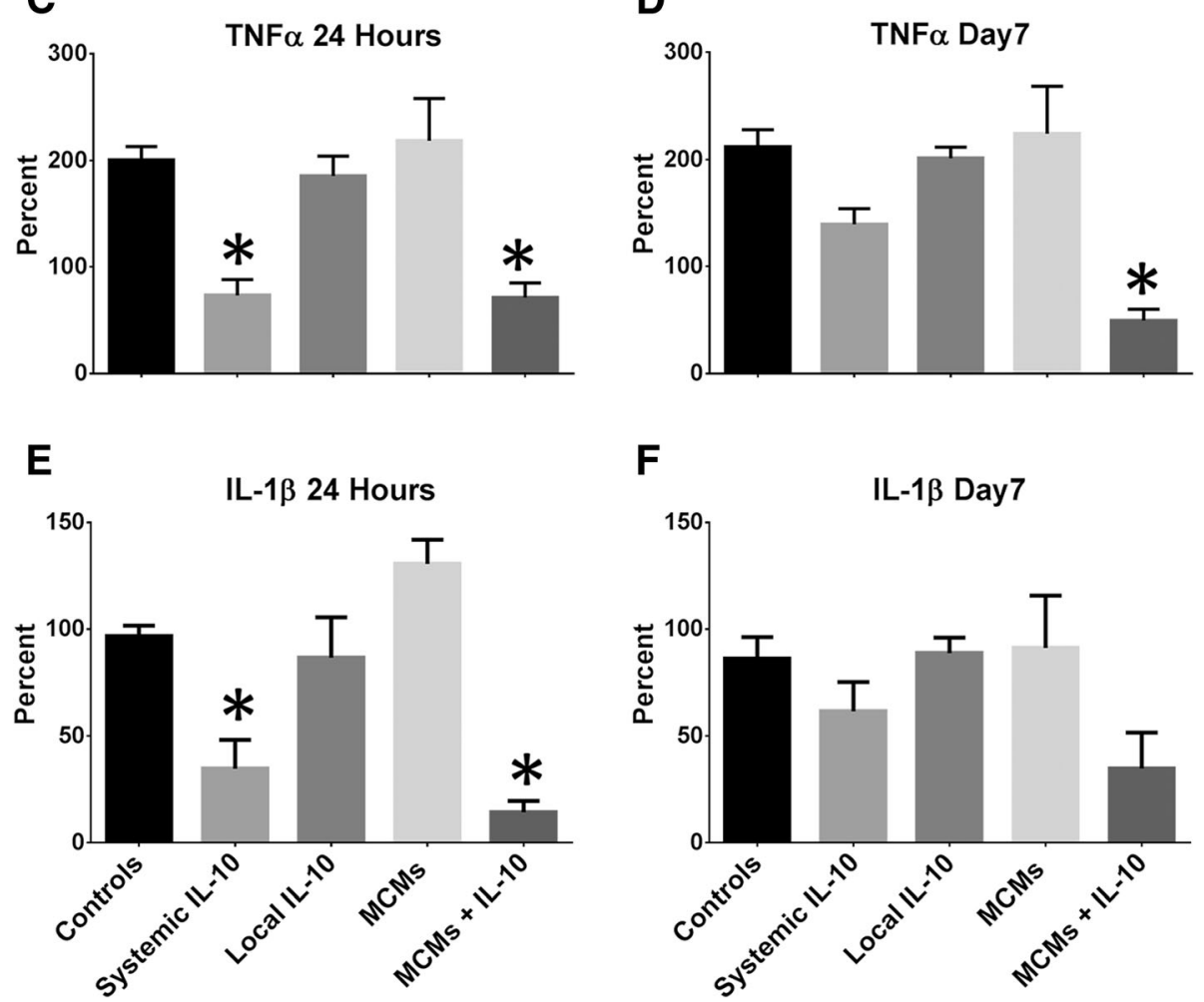

Fig. 3 Assessment of cytokine levels. Spinal cords were harvested at $24 \mathrm{~h}$ and 7 days post-SCI and ELISAs were used to quantify IL-10 (a, b), TNFa $(\mathbf{c}, \mathbf{d})$, and IL-1 $(\mathbf{e}, \mathbf{f})$ in the injury site at each time point. The MCM+IL-10 treated rats had significantly higher levels of IL-10 at both $24 \mathrm{~h}$ and 7 days than the Controls, Local IL-10, and MCMs. Rats with the MCM+IL-10 and Systemic IL-10 treatments had less TNFa and IL-1 $\beta$ than the Controls, Local IL-10, and MCMs at $24 \mathrm{~h}$. There was no significant difference in IL-1 $\beta$ levels at 7 days. All data is presented as percent increase from uninjured rats. ${ }^{*} P<0.05$ in reference to Controls, Local IL-10, and MCMs (Tukey's Test); error bars represent \pm SEM; $n=7$ for each time point

here, macrophages without co-expression of other M1 markers were considered to be M2b [1,30-32]. There was a significant difference between groups in the percentage of cells that were "M1" $\left(\mathrm{F}_{4,14}=5.889, P=0.0054\right.$, ANOVA; Fig. 6d) and "M2b" ( $F_{4,14}=6.958, P=0.0027$, ANOVA; Fig. 6e); however, the percentage of cells that were considered as a later stage "M2c" was negligible for all groups. MCMs+IL-10 had significantly less "M1" cells than Controls $(P=0.0109)$, Local IL-10 $(P=0.0421)$, and MCMs $(P=0.0193)$. Systemic IL-10 was not found to be significantly different than Controls $(P=0.0942)$ or any other treatment group. MCMs+IL-10 had significantly more "M2b" cells than Controls $(P=0.0067)$, Local IL-10 $(P=0.0210)$, and MCMs $(P=0.0095)$, while Systemic IL-10 did not reach significance against Controls $(P=0.0763)$ or any other treatment group.

\section{Immunohistochemistry}

The sagittal spinal cord segments were sectioned $10-\mu \mathrm{m}$ thick and stained for M1 and M2 macrophage antigens, MARCO and CD163, respectively (Fig. 7a-b). There was a significant difference in the ratio of macrophages between the groups $\left(\mathrm{F}_{4,20}=6.374, P=0.0018\right.$, ANOVA; Fig. $7 d$ ). MCMs+IL-10 were found to have a significantly 

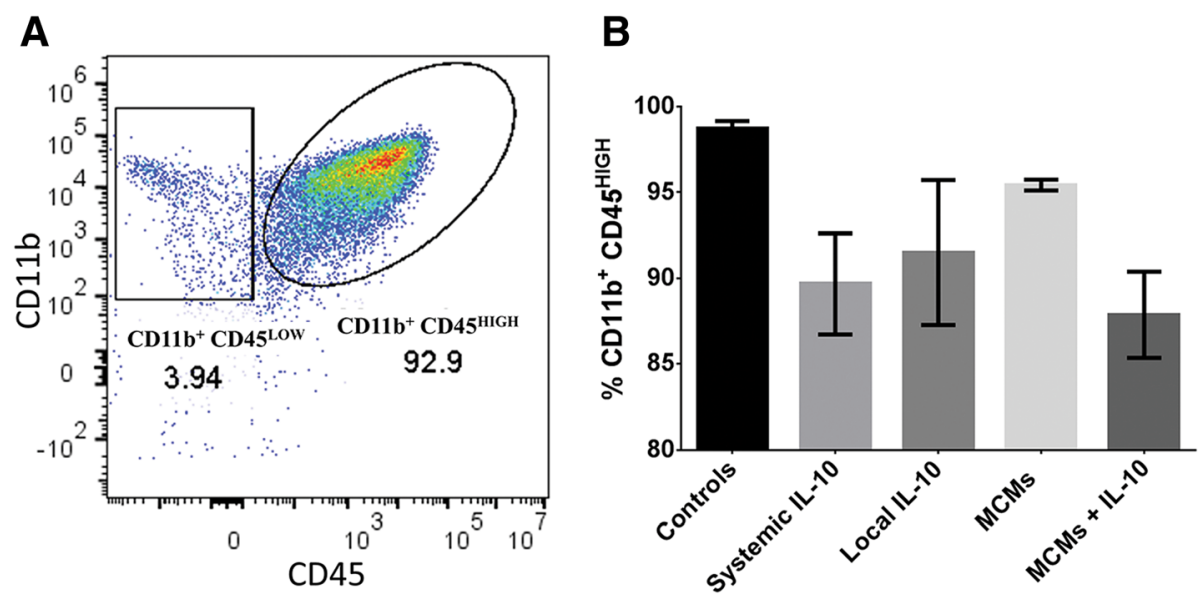

Fig. 4 Flow cytometry performed seven days post-injury. Activated macrophages were distinguished by their expression of CD11b and CD45 (a). No difference was observed in the number of $\mathrm{CD} 11 \mathrm{~b}^{+} \mathrm{CD} 45^{\mathrm{HIGH}}$ macrophages between treatment groups (b). ${ }^{*} P<0.05$ (Tukey's Test); error bars represent $\pm \mathrm{SEM} ; n=3$ for Controls and 4 for all other groups

higher expression of CD163 at $37.96 \pm 0.89 \%$ as compared to the Controls at $19.05 \pm 2.15 \%(P=0.0113)$, Local IL-10 at $13.84 \pm 3.81 \%(P=0.0011)$, and MCMs at $19.84 \pm 2.03 \%$ $(P=0.0158)$. Systemic IL-10 had $24.26 \pm 6.440 \%$ CD163 expression but did not significantly vary from the Controls $(P=0.8450)$, Local IL-10 $(P=0.2870)$, MCMs $(P=0.9071)$, or MCMs+IL-10 $(P=0.0942)$ (Fig. 7c-d).

\section{Functional testing}

On post-operation day one, all the rats' BBB scores had dropped to a score of 0 or 1 . During the 28-day testing period, two Control rats, one Systemic IL-10 rat, two local IL-10 rats, one MCM rat, and one MCM+IL-10 rat were treated for a urinary tract infection. There were no recurrent urinary tract infections. At the end of the 28-day period, improvement in functional scores was seen across all groups. The average BBB scores on day 28 were $13.73 \pm 0.57$ for the Controls, $16.55 \pm 0.91$ for Systemic IL-10, $14.82 \pm 0.97$ for Local IL-10, $16.05 \pm 1.08$ for MCMs, and $18.73 \pm 0.66$ for MCMs+IL-10. A two-way ANOVA determined there was a significant difference between the groups' BBB scores $\left(\mathrm{F}_{4,250}=7.315, P<0.0001\right.$, ANOVA). When compared to the Controls on day 28 , only the MCMs+IL-10 group had significantly higher BBB scores $\left(P_{\text {Systemic IL-10 }}=0.0669, P_{\text {Local IL-10 }}=0.7745, P_{\text {MCMs }}\right.$ $=0.2700, P_{\mathrm{MCMs}}+\mathrm{IL}-10=0.0002$ Fig. $\left.8 \mathrm{a}-\mathrm{c}\right)$.

\section{Axon sparing}

The rubrospinal and reticulospinal tracts were analyzed together as a single entity. The BDA was taken up well throughout all groups, with $955 \pm 123$ axons labeled rostral to the injury. There was a significant difference in the percent of labeled axons that passed through the injury site between the groups $\left(\mathrm{F}_{5,18}=8.539, P=0.0003\right.$, ANOVA). The uninjured rats showed $44.49 \% \pm 1.02 \%$ of the axons rostral are still present caudal to T10. The Controls presented with an average of $15.81 \pm 3.08 \%$, the Systemic IL-10 group with $20.33 \pm 2.17 \%$, the Local IL-10 group with $17.50 \pm 3.80 \%$, the MCMs group with $21.50 \pm 4.61 \%$, and the MCMs+IL-10 group with $35.92 \pm$ $6.55 \%$ of axons crossing the injury site (Fig. 9). A significant difference was found when the percent of axons caudal to the injury of the MCMs+IL-10 group was compared to that of the Controls $(P=0.0216)$ and Local IL-10 $(P=0.0399)$. No other comparisons of groups with contused rats reached significance. Though the percent of axons caudal to the injury of the uninjured rats was significantly greater than the Controls $(P=0.0009)$, Systemic IL-10 $(P=0.0047)$, Local IL-10 $(P=0.0016)$, and MCMs $(P=0.0074)$, the uninjured rats did not reach significance against MCMs+IL-10 $(P=0.6503)$.

The BDA was also taken up well by the motor cortex neurons and there were hundreds of labeled axons rostral to the injury. Although $726 \pm 64$ labeled axons were present in the dorsal corticospinal tract rostral to the injury, virtually no axons crossed the injury site (Fig. 10b, d). Thus, the uninjured rats presented with significantly more dorsal corticospinal tract axons caudal to T10 as compared to all contused groups $\left(\mathrm{F}_{5,12}=55.22, P<0.0001\right.$, ANOVA), with $34.03 \pm 4.57 \%$ and less than $1 \%$, respectively $(P<0.0001$ for all contused groups vs. uninjured rats). The lateral corticospinal tract expressed on each side an average of $32 \pm 4$ axons rostral. The uninjured rats had significantly more lateral corticospinal tract axons caudal to $\mathrm{T} 10$ than all contused groups $\left(\mathrm{F}_{5,12}=32.08, P<0.0001\right.$, ANOVA), with $59.64 \pm 3.7 \%$ and fewer than $10 \%$, respectively $(P<0.0001$ for all contused groups vs. uninjured rats). The ventral corticospinal tract presented with an average of $17 \pm 0.5$ axons rostral to the injury. The uninjured rats presented with significantly more ventral 

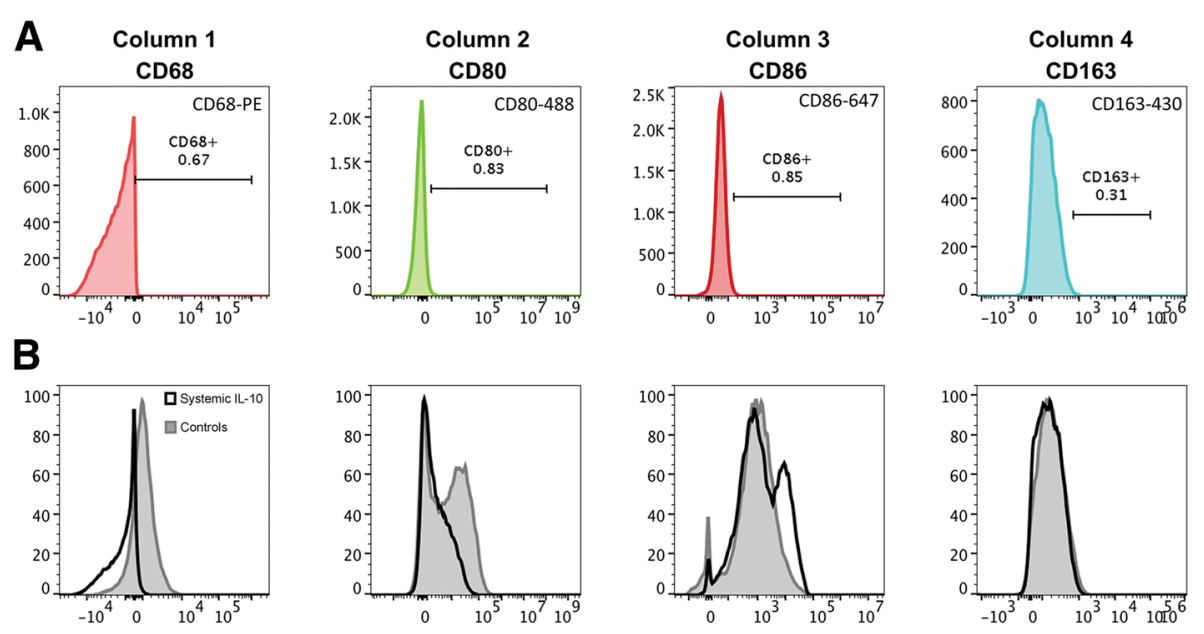

C
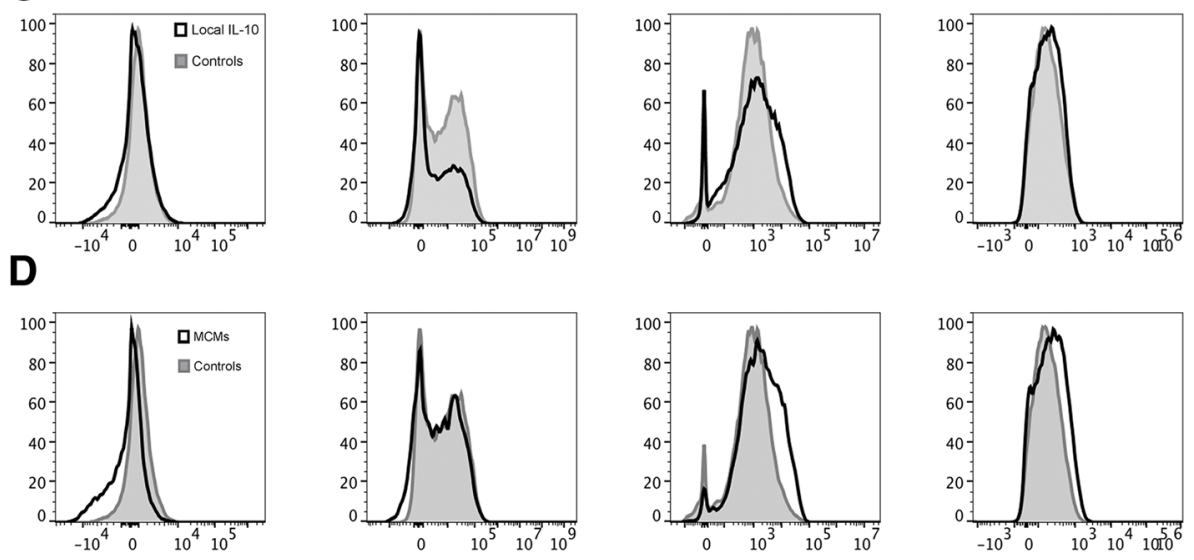

\section{E}
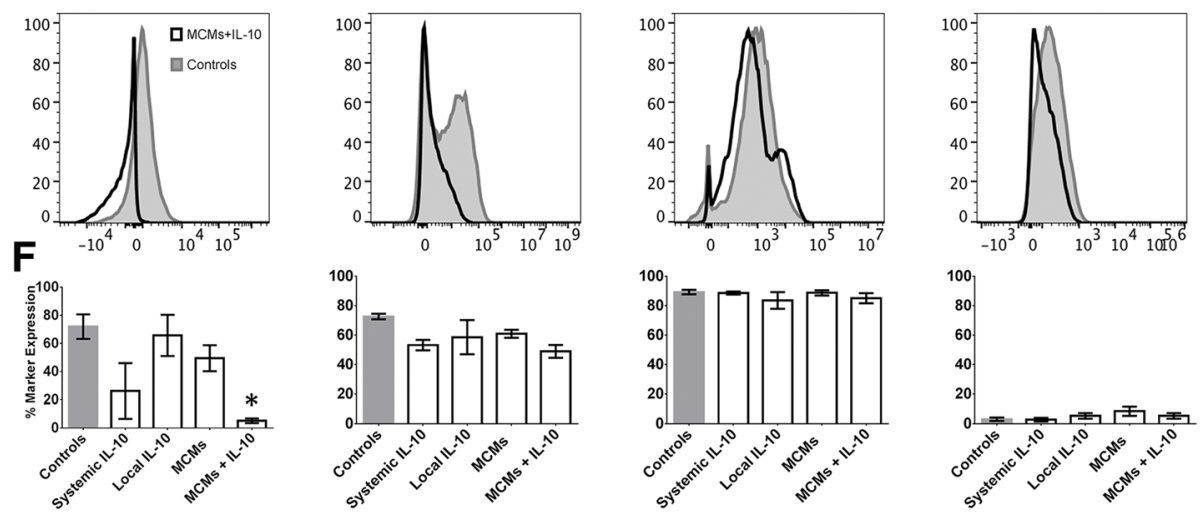

Fig. 5 Macrophages analyzed for M1 and M2 antigens. The gates for M1 specific markers CD68, CD80, M1 or M2b marker CD86, and M2c marker CD163 were set using fluorescence minus one (FMO) (a). Each column represents one antigen. Representative histograms of CD68, CD80, CD86, and CD163 for Controls compared to Systemic IL-10 (b), Local IL-10 (c), MCMs (d), MCMs+IL-10 (e) are displayed. The percentages of antigen expression were quantified (f). ${ }^{*} P<0.05$ (Dunnett's Test); error bars represent $\pm \mathrm{SEM} ; n=3$ for Controls and 4 for all other groups

corticospinal tract axons caudal to T10 than all contused groups $\left(\mathrm{F}_{5,12}=6.154, \mathrm{P}=0.0047\right.$, ANOVA), with $33.19 \pm$ $3.7 \%$ and fewer than $10 \%$, respectively $(P<0.05$ for all contused group vs. uninjured rat comparisons). There were no significant differences between any of the contused groups in any of the corticospinal tracts.

\section{Electrophysiology}

At seven weeks post-SCI, nerve conduction was tested across the injury site. A stimulating electrode was placed rostral to the injury with the recording hook electrode placed caudal to the injury (Fig. 11a). The CDP was consistently recorded and after an injection of lidocaine the 

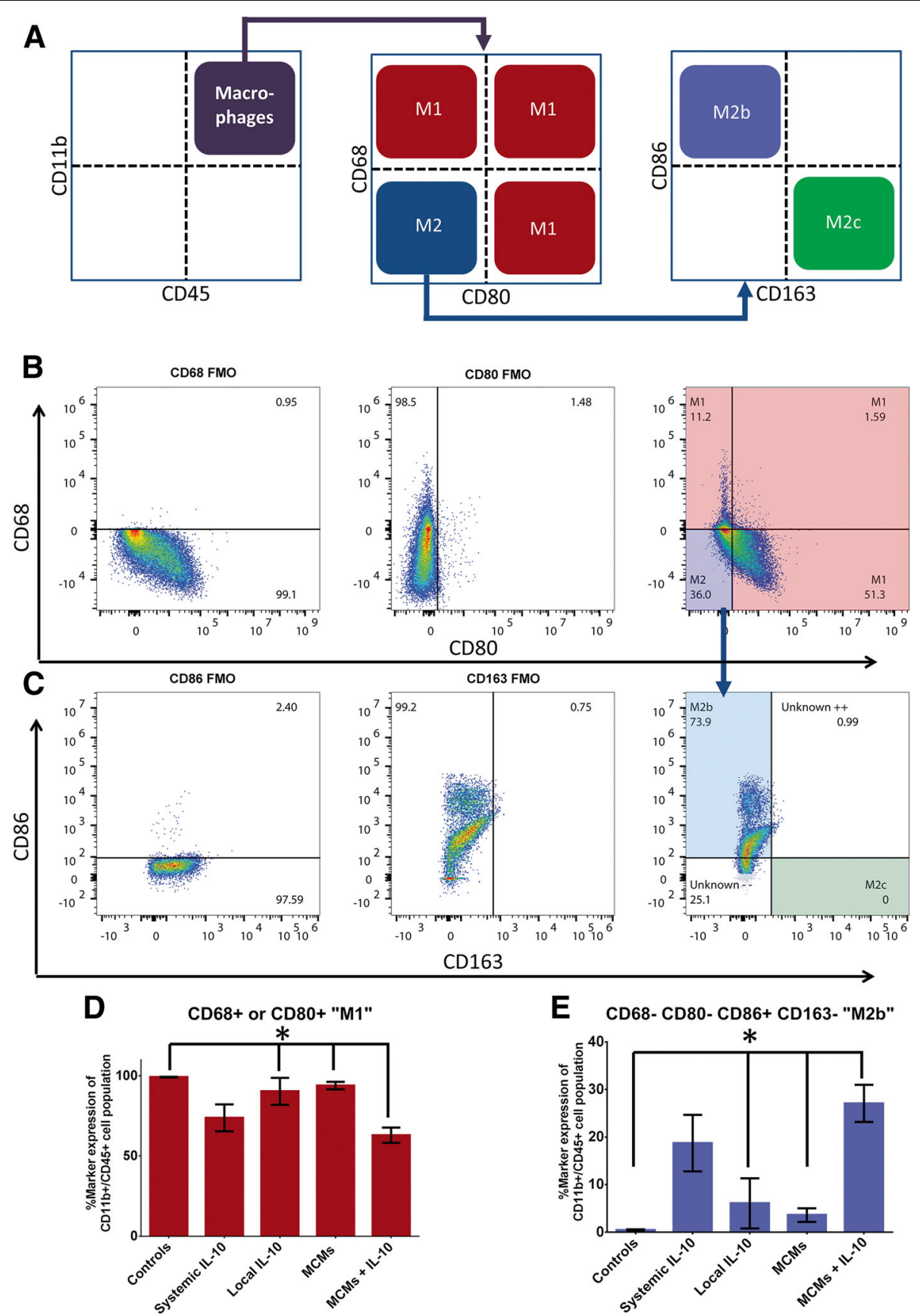

Fig. 6 Percentages of $M 1$ and $M 2$ macrophages. The cells determined to be CD1 $1 b^{+} C D 45^{H I G H}$ macrophages were further analyzed for macrophage phenotype. Cells that were positive for the M1 markers CD68 or CD80 were characterized as "M1" macrophages and the $\mathrm{CD} 68^{-} \mathrm{CD} 80^{-}$macrophages were further analyzed with CD86 and CD163 to distinguish early stage"M2b" and later stage "M2C," as shown in the schematic (a). The FMOs for CD68 and CD80 were used to set the gates and a representative sample of MCMs+IL-10 is shown for the CD68 vs CD80 (b). The FMOs for CD86 and CD163 were used to set the gates for distinguishing "M2b" and "M2c" cells and the CD68 ${ }^{-}$CD80- "M2" macrophages were further analyzed for CD86 vs CD163 (c). Comparing across groups, MCMs+IL-10 had significantly less "M1" macrophages than the Controls, Local IL-10, and MCMs (d). MCMs+IL-10 also had significantly more "M2b" macrophages than the Controls, Local IL-10, and MCMs (e). ${ }^{*} P<0.05$ (Tukey's Test); error bars represent \pm SEM; $n=3$ for Controls and 4 for all other groups

signal was completely removed (Fig. 11b). MCMs+IL-10 had a mean CDP amplitude of $51.45 \pm 23.95 \mu \mathrm{V}$, which was larger than the Controls at $28.44 \pm 7.56 \mu \mathrm{V}$; however, significance was not reached between any contused groups. The uninjured rats had a significantly higher amplitude of $307.3 \pm 47.25 \mu \mathrm{V}\left(\mathrm{F}_{5,12}=26.77, P<0.0001\right.$, ANOVA, Fig. 11c) as compared to all contused groups $(P<0.0001$ for all contused group vs. uninjured rats 

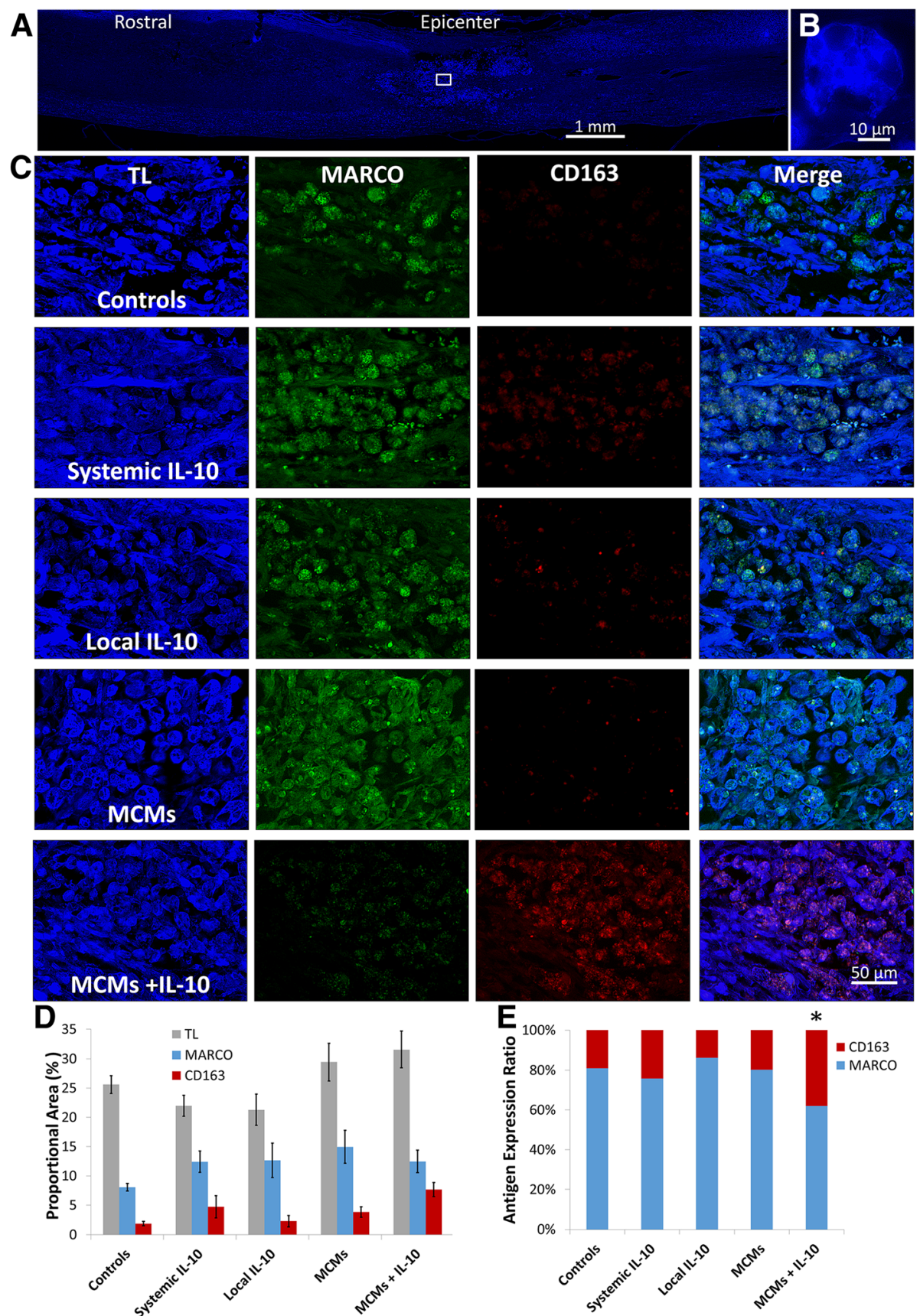

Fig. 7 Histological analysis of IL-10 effect on macrophage phenotype. Sagittal sections of spinal cord containing the injury site were sectioned $10 \mu \mathrm{m}$ thick and stained for all macrophages (TL), M1 macrophages (MARCO), and M2C macrophages (CD163) 7 weeks post-injury. TL stained sagittal section from a Control rat displaying the numerous macrophages labeled in the injury site (a) and a high magnification image showing the amoeboid form of an individual macrophage (b). Box shown in (a) is the location in the epicenter of the injury where representative micrographs of each group were taken (c). The area of tissue stained for macrophages and each phenotype were measured (d) and the ratio of MARCO to CD163 present in each group was calculated (e). The ratio of CD163 to MARCO was significantly higher in the MCMs+IL-10 group when compared to Controls, Local IL-10, and MCMs. ${ }^{*} P<0.05$ (Tukey's Test); error bars represent \pm SEM; $n=5$

comparison). There was also no significant difference in conduction velocity between contused groups. The uninjured rats had a significantly faster conduction velocity of $29.74 \pm 4.11 \mathrm{~m} / \mathrm{s}\left(F_{5}, 12=4.284, P=0.0181\right.$, ANOVA $)$ than the Controls at $13.97 \pm 4.11 \mathrm{~m} / \mathrm{s} \quad(P=0.0146)$ and Local IL-10 at $15.26 \pm 2.10 \mathrm{~m} / \mathrm{s}(P=0.0257)$ but did not 

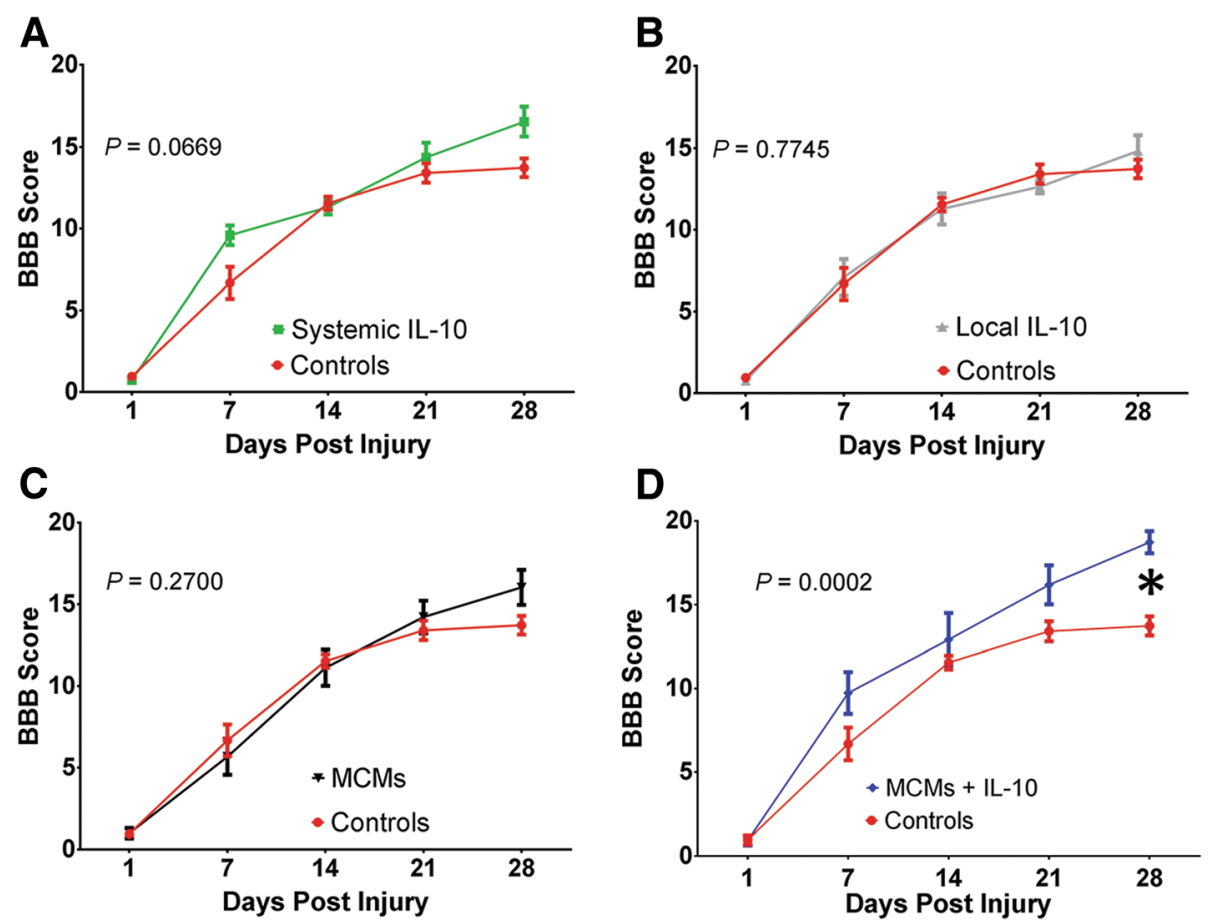

Fig. 8 Assessment of functional recovery. Twenty-eight days post-SCI, BBB scores from the Systemic IL-10 group approached significance when compared to Controls (a), while rats in the Local IL-10 and MCMs groups were not significantly different from Controls (b, c). MCMs+IL-10 was the only group with significantly higher BBB scores than Controls (d). ${ }^{*} P<0.05$ (Dunnett's Test); error bars represent \pm SEM; $n=10$

reach significance against Systemic IL-10 at $20.50 \pm 0.84$ $\mathrm{m} / \mathrm{s}, \mathrm{MCMs}$ at $22.44 \pm 2.19 \mathrm{~m} / \mathrm{s}$ and MCMs+IL-10 at $20.85 \pm 1.00 \mathrm{~m} / \mathrm{s}$ (Fig. 11d).

\section{Lesion size}

Sagittal sections containing the lesion are presented with representatives from each group (Fig. 12a-e). There was a significant difference between the groups with regard to both percent of spinal atrophy $\left(\mathrm{F}_{4,15}=5.272\right.$, $P=0.0074$, ANOVA; Fig. 12f) and area of infarct $\left(\mathrm{F}_{4,15}=13.04, \quad P<0.0001\right.$, ANOVA, Fig. 12g). There was significantly less spinal atrophy in the MCMs + IL-10 group than the Controls $(P=0.0185)$. There was no significant difference in atrophy for the Systemic IL-10, Local IL-10, or the MCMs ( $P_{\text {Systemic IL-10 }}$ $=0.0813, P_{\text {Local IL-10 }}=0.9196, P_{\mathrm{MCMs}}=0.6125 ;$ Fig. $\left.12 \mathrm{f}\right)$. Both MCMs+IL-10 and Systemic IL-10 had significantly smaller area of infarct than the Control group $\left(P_{\text {MCMs }+ \text { IL-10 }}=0.0005, P_{\text {Systemic IL-10 }}=0.0002\right.$; Fig. $\left.12 \mathrm{~g}\right)$. There was no significant difference in infarct size for Local IL-10 or the MCMs when compared against the Controls $\left(P_{\text {Local IL-10 }}=0.1140, P_{\mathrm{MCMs}}=0.9615 ;\right.$ Fig. $\left.12 \mathrm{~g}\right)$.

\section{Discussion}

As shown previously, mineral coatings have a high protein-binding propensity and the capability to release proteins over a controllable time frame with high levels of protein biological activity [18-20, 33-36]. In this study, we hypothesized a local sustained release of IL-10 from mineral coatings would reduce the prolonged inflammation that occurs after SCI. The in vitro release profile indicates an initial burst of IL-10 for 2 days, followed by a continuous release of IL-10 for at least 17 days, evidence that the coating has the ability to maintain protein delivery for a length of time through the initial inflammatory period post-SCI $[2,3]$.

\section{IL-10's effect on inflammation}

Normal wound healing in skin or muscle occurs over three defined stages: inflammation, proliferation, and remodeling. Throughout healing, macrophages exist on a continuum from M1 inflammatory macrophages to M2 anti-inflammatory macrophages dictated by the extracellular environment. In the inflammatory stage, M1 macrophages aid the innate immunity by inducing inflammation through the production of TNF $\alpha$ and IL-1 $\beta$, while phagocytosing bacteria and debris [1, 37]. As proliferation begins, M1 macrophages gradually change phenotype to a variety of M2 macrophage subsets with different functions. Generally, M2 macrophages attenuate the production of pro-inflammatory cytokines and reactive oxygen species (ROS), in addition to having tissue-repairing properties. The production of IL-10 is traditionally attributed to the M2b phenotype $[31,38]$ 

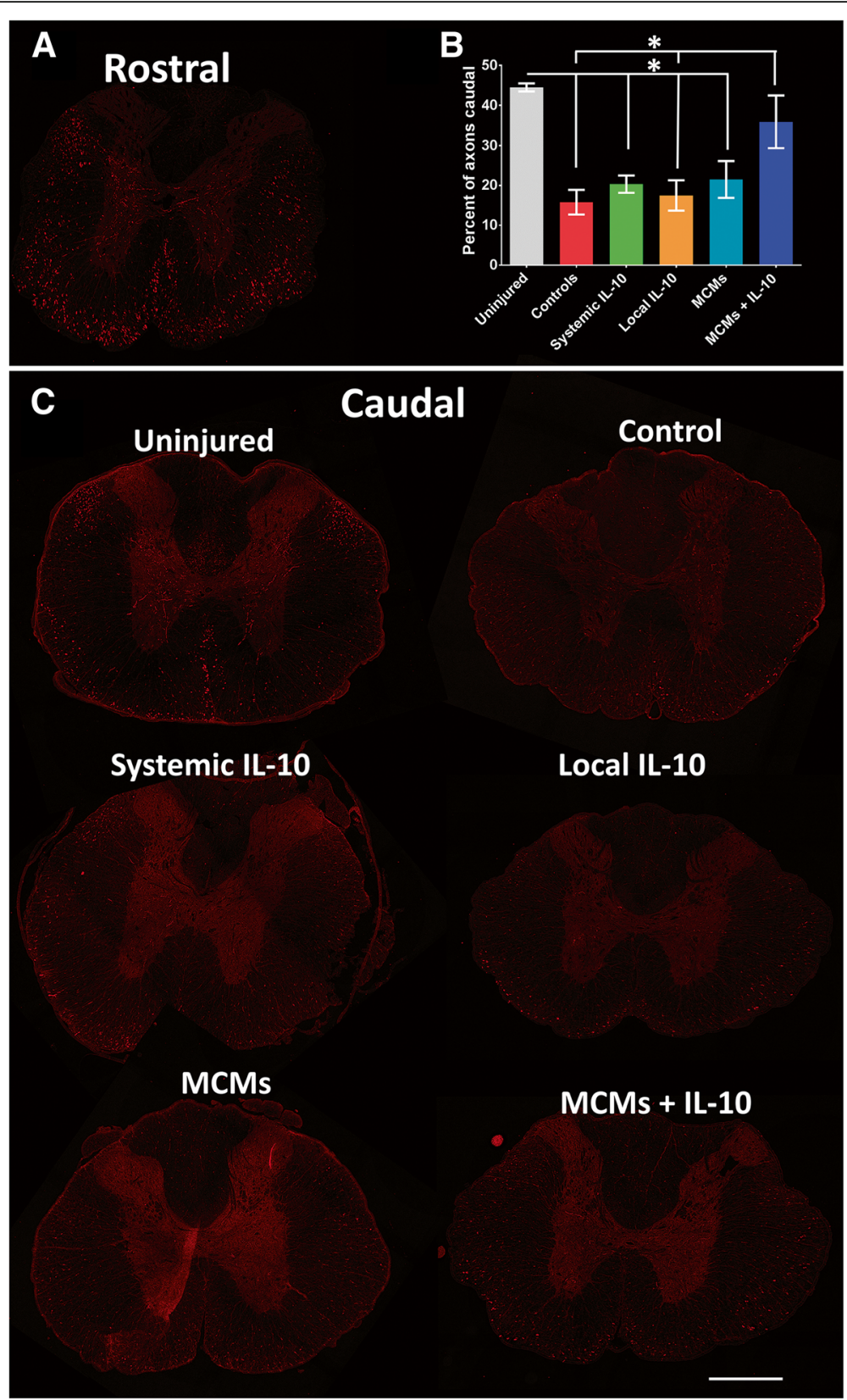

Fig. 9 Axon tracing in brainstem tracts. Twenty-eight days post-SCl, rats were injected with BDA in the red nucleus and reticular formation and harvested 21 days after injection. Transverse sections displayed are rostral to the injury site (a), caudal in an uninjured rat, Control, Systemic IL-10, Local IL-10, MCMs, and MCMs+IL-10 (c). The percentage of axons that passed through to the caudal sections was calculated (b). The BDA injected rats had an average of $977 \pm 93$ axons labeled rostral to the injury. Uninjured rats had a significantly higher number of axons extending through to the caudal sections compared to all groups except the MCMs+IL-10 group. The rats treated with MCMs+IL-10 had a significantly higher percentage of labeled axons caudal to the injury, 35.92 $\pm 6.559 \%$, when compared to Controls $15.81 \pm 3.081 \%$ and Local IL-10 $17.50 \pm 3.804 \%$. Red represents BDA labeled axons; blue represents DAPI; ${ }^{*} P<0.05$ (Tukey's Test); error bars represent \pm SEM; $n=4$ per group; scale bar $=500 \mu m$

and acts in tissue remodeling during the proliferative stage of muscle and skin wound healing [8,39]. During healing, M2c macrophages remain to aid in the remodeling phase [39]. However, defined stages of healing are not present post-SCI $[1,4]$. Without proper termination of the inflammatory stage, the presence of activated macrophages (M1 and M2) may last for years [1,39].

Post-SCI, the poor transition of macrophages complicates healing [39-41]. Binding of IL-10 to the IL-10 receptor activates the Jak/STAT pathway, which results in 

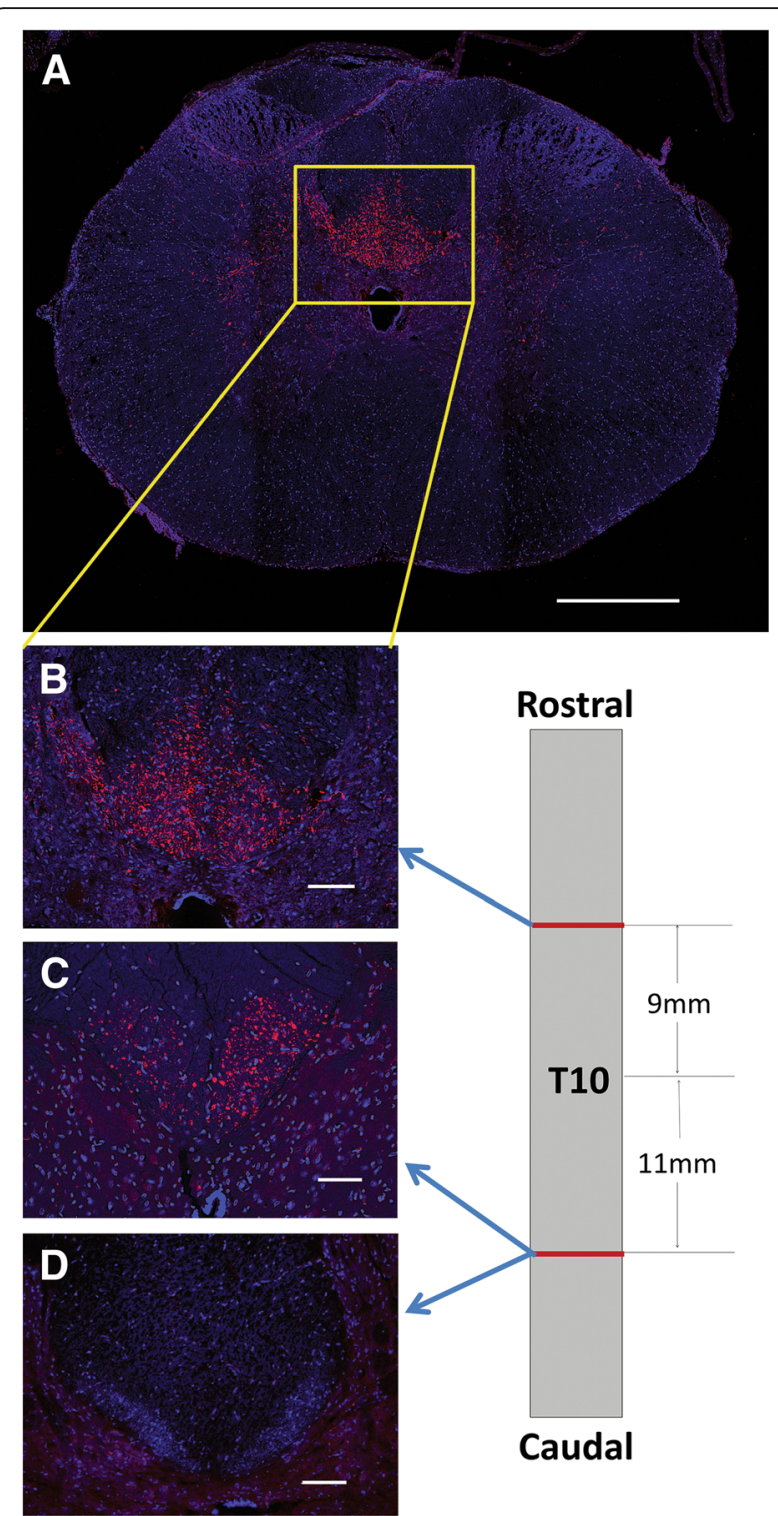

Fig. 10 Axon tracing in the corticospinal tracts. Twenty-eight days post-SCl, rats were injected with BDA in the motor cortex and harvested 21 days after injection. Transverse sections rostral to the T10 level had an average of $739 \pm 58$ labeled axons in the dorsal corticospinal tract $(\mathbf{a}, \mathbf{b})$ and uninjured rats had an average of $97 \pm$ 56 in the region caudal to the T10 level $(\mathbf{c})$, which was significantly more than all other groups $(P<0.0001)$. Virtually no axons were labeled in the dorsal corticospinal tract caudal to the injury site in Controls (d) or any of the treatment groups and there was no significant difference between any of the groups that underwent an $\mathrm{SCl}$. Red represents BDA labeled axons; blue represents DAPI; $n=3$ per group; scale bars $=500 \mu \mathrm{m}(\mathbf{a}), 100 \mu \mathrm{m}(\mathbf{b}-\mathbf{d})$

a reduction of pro-inflammatory cytokines released from macrophages/microglia [12]. One mechanism by which IL-10 treatment is thought to improve functional recovery post-SCI is through macrophage deactivation: hindering the production of pro-inflammatory cytokines prevents further damage to the spinal cord by attenuating cell death

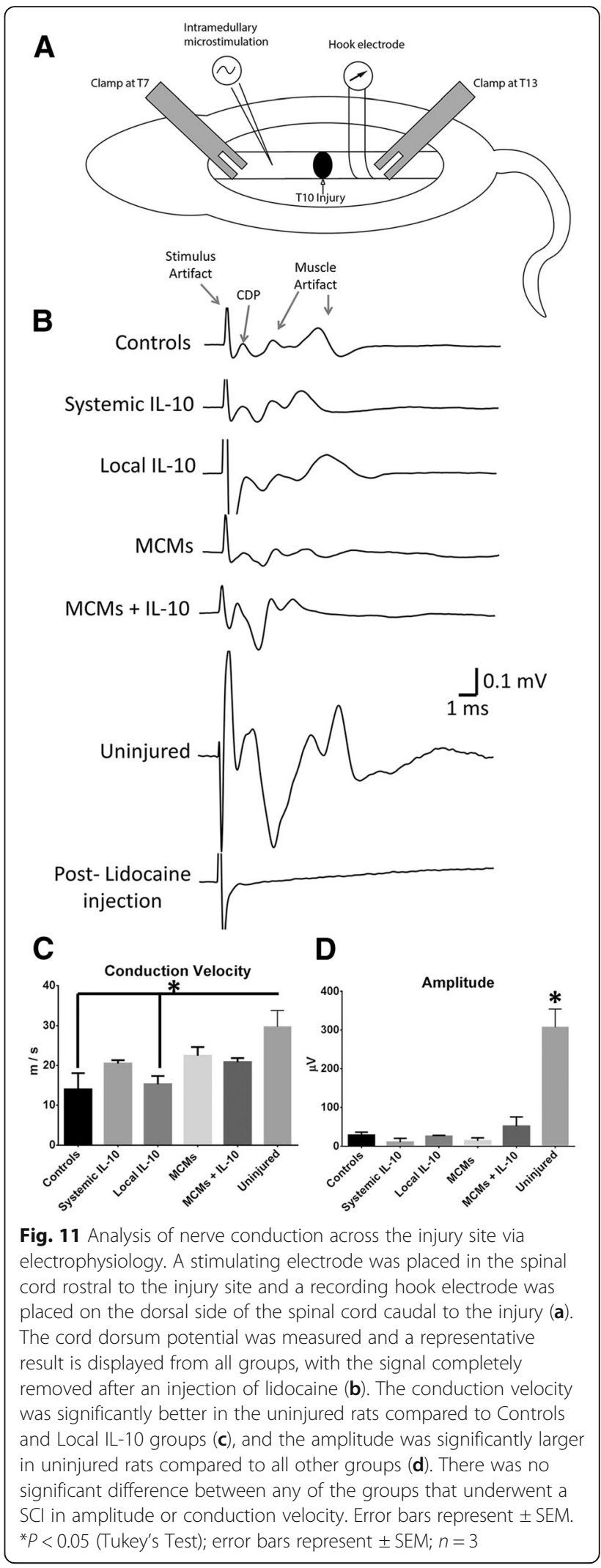



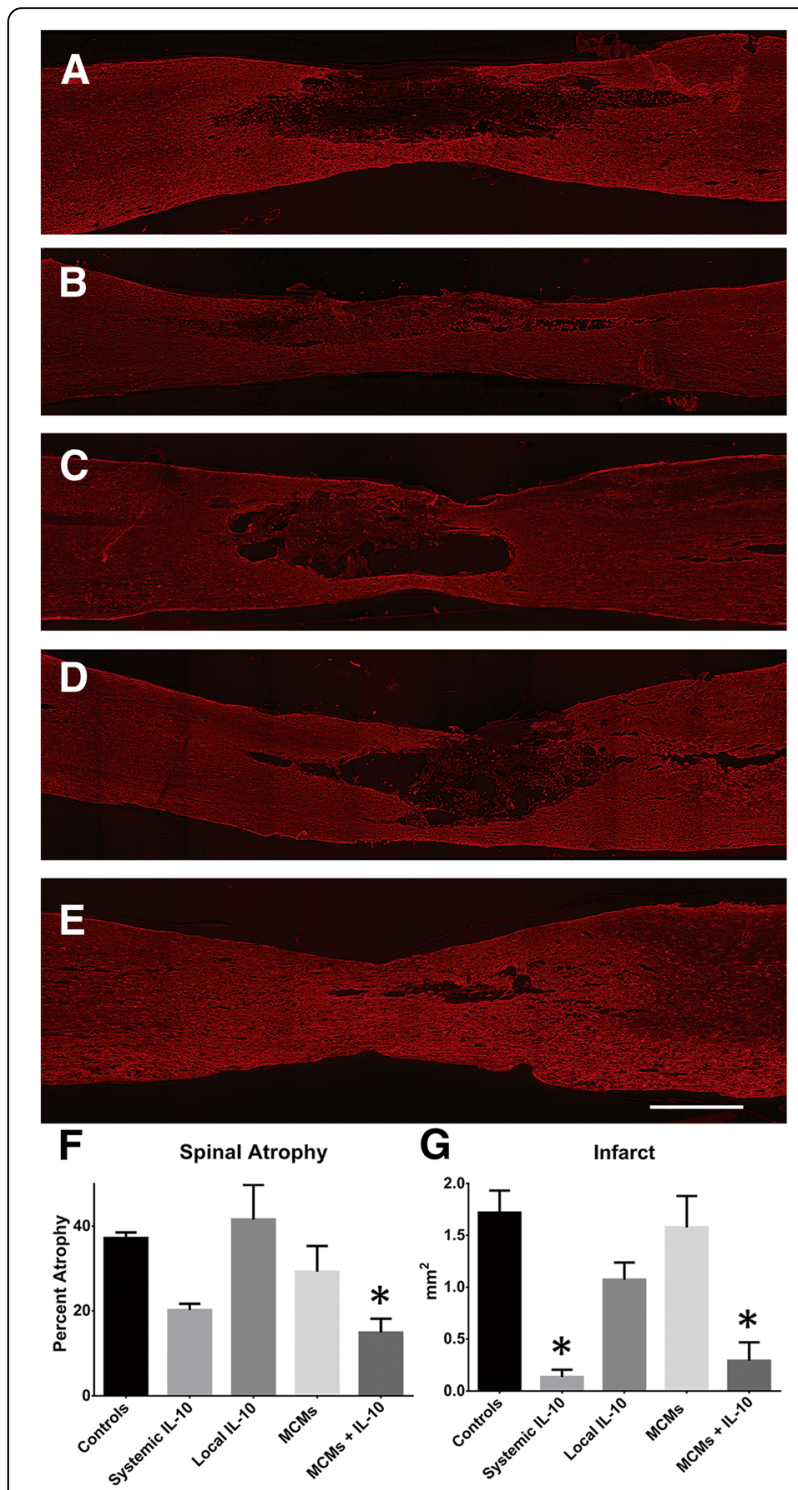

Fig. 12 Analysis of IL-10 effect on lesion size and spinal atrophy. Sagittal sections of spinal cord containing the injury site were sectioned $10 \mu \mathrm{m}$ thick and GFAP positive astrocytes were labeled in Controls (a), Systemic IL-10 (b), Local IL-10 (c), MCMs (d), and MCMs $+\mathrm{IL}-10$ (e). The spinal cord thickness was measured $5 \mathrm{~mm}$ rostral to the epicenter, at the epicenter, and $5 \mathrm{~mm}$ caudal to the epicenter and the percent in reduced thickness at the injury site was calculated (f). The MCMs+IL-10 was the only group with significantly less spinal atrophy than Controls. The infarct was measured as the area of tissue outlined by reactive astrocytes $(\mathbf{g})$. Both the Systemic IL-10 and MCMs+IL-10 had a significantly smaller infarct area when compared to the Controls. ${ }^{*} P<0.05$ (Dunnett's Test); error bars represent \pm SEM; $n=4$; scale bar $=1 \mathrm{~mm}$

$[42,43]$ and blood-spinal cord barrier disruption [44], in addition to reducing ROS and neurotoxic substance production. These benefits have been observed in previous studies where IL-10 induced nerve growth factor production in astrocytes and reduced astrogliosis post-TBI in rats $[6,45]$.
In this study, the MCMs+IL-10 group observed a significant increase in IL-10 at both $24 \mathrm{~h}$ and 7 days post-SCI (Fig. 3a-b). In accordance with previous studies, the Systemic IL-10 treatment attenuated TNF $\alpha$ and IL-1 $\beta$ production at $24 \mathrm{~h}$ post-SCI, but failed to reach significance at 7 days post-SCI [14, 46, 47]. The MCMs +IL-10 group did significantly attenuate the production of TNFa at 7 days post-SCI, proving the sustained release of IL-10 effective. However, there was no significant difference in IL-1 $\beta$ production at 7 days post-SCI (Fig. 3f). In agreement with the cytokine analysis, MCMs+IL-10 observed a significant decrease in the number of "M1" macrophages as compared to Controls at 7 days post-SCI, evaluated with flow cytometry (Fig. 6d). Although there was no difference in the expression of the M2c marker CD163 between any of the groups 7 days post-SCI, there was a significant increase in the "M2b" population $\left(\mathrm{CD} 11 \mathrm{~b}^{+} \mathrm{CD} 45^{\mathrm{HIGH}} \mathrm{CD} 68^{-}\right.$ $\left.\mathrm{CD}^{-} 0^{-} \mathrm{CD}^{+} 6^{+} \mathrm{CD} 163^{-}\right)$in the $\mathrm{MCM}+\mathrm{IL}-10$ group (Fig. 6e). The sustained release of IL-10 is likely contributing to the decreased expression of M1 macrophage markers, but complete conversion to an M2c expressing CD163 was not observed at the 7-day time point. Immunohistochemistry analysis at 7 weeks post-SCI, however, did show a significant increase in the ratio of CD163:MARCO (M2c:M1) in MCMs+IL-10 as compared to Controls (Fig. 7c). Co-expression of MARCO and CD163 was observed, indicating that these macrophages lie between M1 and late stage M2 on the continuum but lean closer to M2 with the MCMs+IL-10 treatment as compared to Controls (Fig. 7). This is likely beneficial as M2c macrophages $\left(\mathrm{CD}_{163}{ }^{+}\right)$are found in the later stages of wound healing $[1,37,39]$.

\section{Using IL-10 to treat SCI}

IL-10 treatment has been shown to improve functional recovery in Sprague-Dawley rats post-SCI [13-15]. Here, the MCMs+IL-10 group had the highest functional score on day 28 and was the only group to reach significance when compared to the Controls (Fig. 8d). In addition, IL-10 treatment has previously reduced lesion size post-SCI $[14,48]$. We observed similar reductions in lesion size, with a significant reduction in infarct size with both the Systemic IL-10 treatment and the MCMs +IL-10 treatment as compared to Controls. However, there was no significant difference between MCMs + IL-10 and Systemic IL-10 in atrophy $(P=0.9358$; Fig. 12f) or infarct size $(P=0.9791$; Fig. 12g).

The MCMs+IL-10 group also expressed the greatest percent of spared axons in the reticulospinal and rubrospinal tracts, which was the only group significantly higher than the Controls. Though functional recovery was observed across all groups, the dorsal corticospinal tract presented with virtually no axons 
crossing the injury site in any of the five contused groups, unlike the reticulospinal and rubrospinal tracts. This data, in conjunction with the functional recovery assessed through BBB scores, suggests changes involving spared axons may have occurred within the spinal cord to permit functional recovery.

The number of axons spared in the rubrospinal and reticulospinal tracts suggests a plastic capability of the rat central nervous system (CNS) which allows for heavier reliance on these tracts for motor function. Both the rubrospinal and reticulospinal tracts are known to participate in motor function in healthy models, specifically through limb movement, though to different capacities. The rubrospinal tract maintains greater control of more precise movements and the reticulospinal tract expresses control of larger, gross locomotor movement and rhythm [49-54]. It is possible that the CNS is utilizing the spared axons in these tracts, which already express an innate participation in locomotor function, to regain motor capabilities after injury. Animal models have shown the rubrospinal tract is capable of absorbing the role of the corticospinal tract (CST) in the event of injury [55-59]. Although the rubrospinal tract is well developed in lower mammals (i.e., cats and rats), its importance in upper mammals appears to have diminished with the evolutionary development of the CST [60]. This may hinder translation to human models, which do not express a prominent rubrospinal tract [61].

Another possible explanation is that spontaneous axonal sprouting may have occurred and aided in improving functional recovery in the MCM+IL-10 group. Previous studies have shown the ability of various tracts within the spinal cord to express axonal sprouting [55, 62-65]. The axon tracer used in this study, BDA, does not cross synapses. Thus if there was axonal sprouting and synapsing, it would not have been detected.

No significant difference was found between contused groups for conduction velocity or amplitude (Fig. 11c-d). With few axons extending through the injury site post-SCI, the CST likely created a very small signal in all the rats, regardless of treatment. The location of the rubrospinal and reticulospinal tracts, along with the placing of the recording electrode, may have impacted the results. The rubrospinal and reticulospinal tracts are located deep and laterally in the spinal cord. With the receiving electrode placed gently on the dorsal side of the spinal cord, voltage from action potentials in deeper tracts would be reduced due to distance.

\section{Conclusion}

Following a SCI, diverse cellular and molecular responses result in abnormal environmental conditions, which both greatly hinder axon growth and result in further cell death. The present study demonstrates the use of MCMs loaded with IL-10 to provide a sustained release of the anti-inflammatory cytokine in order to establish a less severe environment and allow for axon sparing. The results are promising, with in vitro results expressing a release profile of IL-10 for at least 17 days. This extended release is carried over in vivo resulting in lower levels of TNF $\alpha$ and IL-1 $\beta$, lower levels of "M1" macrophages, greater numbers of surviving axons, enhanced functional recovery, and a smaller lesion size in those rats treated with IL-10-bound MCMs. These outcomes exemplify the neuro-protective properties of IL-10 when delivered over a prolonged period of time. Interestingly, however, the lack of variation among the groups with regard to axon sparing in the corticospinal tracts calls for further studies, especially when taking into the account the considerable differences observed in the rubrospinal and reticulospinal tracts of the groups. Further investigations, which explore such topics as the release of multiple therapeutic proteins and the use of an axon tracer that has the ability to cross synapses, are necessary to better enhance our understanding.

\section{Abbreviations \\ AP: Anterior-posterior; BBB: Basso-Beattie-Bresnahan; BDA: Biotinylated dextran amine; BSA: Bovine serum albumin; CDP: Cord dorsum potential; CNS: Central nervous system; CST: Corticospinal tract; DAPI: 4',6-diamidino-2- phenylindole; DV: Dorsal-ventral; EDS: Energy dispersive spectroscopy; ELISA: Enzyme-linked immuno-sorbent assay; FMO: Fluorescence minus one; GFAP: Glial fibrillary acidic protein; IL-1 $\beta$ : Interluekin-1 beta; IL-10: Interleukin- 10; MARCO: Macrophage receptor with collagenous structure; MC: Motor cortex; MCMs: Mineral Coated Microparticles; ML: Medial-lateral; mSBF: Modified simulated body fluid; nDS: Normal donkey serum; PFA: Paraformaldehyde; RF: Reticular formation; RN: Red nucleus; ROS: Reactive oxygen species; SCI: Spinal Cord Injury; SEM: Standard Error of the Mean; TNFa: Tumor necrosis factor-alpha; $\beta$-TCP: $\beta$-tricalcium phosphate}

\section{Acknowledgements}

We would like to thank the Bryon Riesch Paralysis Foundation and the Fraternal Order of Eagles for their generous financial support of this study. We also wish to thank the U.W. Carbone Cancer Center for their help with tissue sectioning, immunohistochemistry and flow cytometry (N.C.I. \# P30 (A014520).

\section{Funding}

This study was funded by a research grant from the Bryon Riesch Paralysis Foundation and a generous donation from the Fraternal Order of Eagles (Grant number: 133-PRJ84LQ).

\section{Availability of data and materials \\ The datasets used and analyzed during the current study are included within the article and its additional files. All material used in this manuscript will be made available to researchers subject to confidentiality.}

\section{Authors' contributions}

All authors had full access to all the data in the study and take responsibility for the integrity of the data and the accuracy of the data analysis. ASH, DJH, KAR, ASK, and WLM contributed to the study concept and design. ASH, DJH, KAR, ASK, BJT, MEF, ASK, DJP, AVG, ERM, MTA, and AGA contributed to the acquisition of data. ASH, DJH, KAR, MEF, and WLM contributed to the analysis and interpretation of data. DJH, MEF, BJT, ASK, WLM contributed to the drafting of the manuscript and critical revision of the article. ASH and DJH contributed to the statistical analysis:. ASH obtained funding. All authors read and approved the final manuscript. 


\section{Ethics approval and consent to participate}

All experimental procedures were performed following the National Institutes of Health Guide for the care and use of laboratory animals and in accordance with protocols approved by the University of WisconsinMadison Animal Use \& Care Committee.

\section{Consent for publication}

Not applicable.

\section{Competing interests}

W.L.M. is a co-founder and stockholder of Dianomi Therapeutics. The other authors declare that they have no competing interests.

\section{Publisher's Note}

Springer Nature remains neutral with regard to jurisdictional claims in published maps and institutional affiliations.

\section{Author details}

'Department of Neurological Surgery, University of Wisconsin, Madison, WI 53792, USA. ${ }^{2}$ Department of Biomedical Engineering, University of Wisconsin, Madison, WI 53706, USA. ${ }^{3}$ Department of Orthopedics and Rehabilitation, University of Wisconsin, Madison, WI 53705, USA.

\section{Received: 20 December 2018 Accepted: 9 April 2019}

\section{Published online: 30 April 2019}

\section{References}

1. Gensel JC, Zhang B. Macrophage activation and its role in repair and pathology after spinal cord injury. Brain Res. 2015;1619:1-11.

2. Almad A, Sahinkaya FR, McTigue DM. Oligodendrocyte fate after spinal cord injury. Neurotherapeutics. 2011;8(2):262-73.

3. Lu JK, Ashwell KWS, Waite P. Advances in secondary spinal cord injury - role of apoptosis. Spine. 2000;25(14):1859-66.

4. Kigerl KA, Gensel JC, Ankeny DP, Alexander JK, Donnelly DJ, Popovich PG. Identification of two distinct macrophage subsets with divergent effects causing either neurotoxicity or regeneration in the injured mouse spinal cord. J Neurosci. 2009;29(43):13435-44.

5. Chan CC. Inflammation: beneficial or detrimental after spinal cord injury? Recent Pat CNS Drug Discov. 2008;3(3):189-99.

6. Balasingam V, Yong WW. Attenuation of astroglial reactivity by interleukin-10. J Neurosci. 1996;16(9):2945-55.

7. Shechter R, London A, Varol C, Raposo C, Cusimano M, Yovel G, et al. Infiltrating blood-derived macrophages are vital cells playing an antiinflammatory role in recovery from spinal cord injury in mice. PLoS Med. 2009;6(7):e1000113.

8. Thompson CD, Zurko JC, Hanna BF, Hellenbrand DJ, Hanna A. The therapeutic role of interleukin-10 after spinal cord injury. J Neurotrauma. 2013;30(15):1311-24.

9. Fuchs AC, Granowitz EV, Shapiro L, Vannier E, Lonnemann G, Angel JB, et al. Clinical, hematologic, and immunologic effects of interleukin-10 in humans. J Clin Immunol. 1996;16(5):291-303.

10. Fiorentino DF, Zlotnik A, Mosmann TR, Howard M, O'Garra A. IL-10 inhibits cytokine production by activated macrophages. J Immunol. 1991;147(11): 3815-22.

11. Zhou Z, Peng X, Insolera R, Fink DJ, Mata M. Interleukin-10 provides direct trophic support to neurons. J Neurochem. 2009;110(5):1617-27 PubMed PMID: 19575707. Pubmed Central PMCID: 2737090.

12. Xin J, Wainwright DA, Mesnard NA, Serpe CJ, Sanders VM, Jones KJ. IL-10 within the CNS is necessary for CD4+ T cells to mediate neuroprotection. Brain Behav Immun. 2011;25(5):820-9.

13. Zhou Z, Peng X, Insolera R, Fink DJ, Mata M. IL-10 promotes neuronal survival following spinal cord injury. Exp Neurol. 2009;220(1):183-90.

14. Bethea JR, Nagashima $H$, Acosta MC, Briceno C, Gomez F, Marcillo AE, et al. Systemically administered interleukin-10 reduces tumor necrosis factoralpha production and significantly improves functional recovery following traumatic spinal cord injury in rats. J Neurotrauma. 1999;16(10):851-63.

15. Jackson CA, Messinger J, Peduzzi JD, Ansardi DC, Morrow CD. Enhanced functional recovery from spinal cord injury following intrathecal or intramuscular administration of poliovirus replicons encoding $\| L-10$. Virology. 2005;336(2):173-83.
16. Radwanski E, Chakraborty A, Van Wart S, Huhn RD, Cutler DL, Affrime MB, et al. Pharmacokinetics and leukocyte responses of recombinant human interleukin-10. Pharm Res. 1998;15(12):1895-901.

17. Kastin AJ, Akerstrom V, Pan W. Interleukin-10 as a CNS therapeutic: the obstacle of the blood-brain/blood-spinal cord barrier. Brain research Mo Brain Res 2003;114(2):168-171.

18. Yu X, Khalil A, Dang PN, Alsberg E, Murphy WL. Multilayered inorganic microparticles for tunable dual growth factor delivery. Adv Funct Mater. 2014:24(20):3082-93.

19. Suarez-Gonzalez D, Barnhart K, Migneco F, Flanagan C, Hollister SJ, Murphy WL. Controllable mineral coatings on PCL scaffolds as carriers for growth factor release. Biomaterials. 2012;33(2):713-21.

20. Hanna A, Thompson DL, Hellenbrand DJ, Lee JS, Madura CJ, Wesley MG, et al. Sustained release of neurotrophin-3 via calcium phosphate-coated sutures promotes axonal regeneration after spinal cord injury. J Neurosc Res. 2016;94(7):645-52

21. Hellenbrand DJ, Hanna A. Treating spinal cord injury via sustained drug delivery from calcium phosphate coatings. Neural Regen Res. 2016;11(8): 1236-7.

22. Song JW, Li K, Liang ZW, Dai C, Shen XF, Gong YZ, et al. Low-level laser facilitates alternatively activated macrophage/microglia polarization and promotes functional recovery after crush spinal cord injury in rats. Sci Rep. 2017;7(1):620.

23. Dyck S, Kataria H, Alizadeh A, Santhosh KT, Lang B, Silver J, et al. Perturbing chondroitin sulfate proteoglycan signaling through LAR and PTPsigma receptors promotes a beneficial inflammatory response following spinal cord injury. J Neuroinflammation. 2018;15(1):90.

24. Alizadeh A, Santhosh KT, Kataria H, Gounni AS, Karimi-Abdolrezaee S. Neuregulin-1 elicits a regulatory immune response following traumatic spinal cord injury. J Neuroinflammation. 2018:15(1):53.

25. de Haas AH, Boddeke HW, Biber K. Region-specific expression of immunoregulatory proteins on microglia in the healthy CNS. Glia. 2008; 56(8):888-94

26. Remington LT, Babcock AA, Zehntner SP, Owens T. Microglial recruitment, activation, and proliferation in response to primary demyelination. Am J Pathol. 2007:170(5):1713-24.

27. Turtzo LC, Lescher J, Janes L, Dean DD, Budde MD, Frank JA. Macrophagic and microglial responses after focal traumatic brain injury in the female rat. J Neuroinflammation. 2014;11:82.

28. Basso DM, Beattie MS, Bresnahan JC. A sensitive and reliable locomotor rating-scale for open-field testing in rats. J Neurotrauma. 1995;12(1):1-21.

29. Hellenbrand DJ, Kaeppler KE, Hwang E, Ehlers ME, Toigo RD, Giesler JD, et al. Basic techniques for long distance axon tracing in the spinal cord. Microsc Res Tech. 2013;76(12):1240-9

30. Zhang B, Bailey WM, Braun KJ, Gensel JC. Age decreases macrophage IL-10 expression: implications for functional recovery and tissue repair in spinal cord injury. Exp Neurol. 2015;273:83-91.

31. Edwards JP, Zhang X, Frauwirth KA, Mosser DM. Biochemical and functional characterization of three activated macrophage populations. J Leukoc Biol. 2006;80(6):1298-307.

32. Martinez FO, Gordon $\mathrm{S}$. The $\mathrm{M} 1$ and $\mathrm{M} 2$ paradigm of macrophage activation: time for reassessment. F1000prime Rep. 2014;6:13.

33. Jongpoiboonkit L, Franklin-Ford T, Murphy WL. Mineral-coated polymer microspheres for controlled protein binding and release. Adv Mater. 2009; 21(19):1960-3.

34. Lee JS, Lu Y, Baer GS, Markel MD, Murphy WL. Controllable protein delivery from coated surgical sutures. J Mater Chem. 2010;20(40):8894-903.

35. Suarez-Gonzalez D, Barnhart K, Saito E, Vanderby R Jr, Hollister SJ, Murphy WL. Controlled nucleation of hydroxyapatite on alginate scaffolds for stem cell-based bone tissue engineering. J Biomed Mater Res A. 2010; 95(1):222-34

36. Yu X, Biedrzycki AH, Khalil AS, Hess D, Umhoefer JM, Markel MD, et al. Nanostructured mineral coatings stabilize proteins for therapeutic delivery. Adv Mater. 2017:29(33):1701255.

37. Lech M, Anders HJ. Macrophages and fibrosis: how resident and infiltrating mononuclear phagocytes orchestrate all phases of tissue injury and repair. Biochim Biophys Acta. 2013;1832(7):989-97.

38. Mosser DM, Edwards JP. Exploring the full spectrum of macrophage activation. Nat Rev Immunol. 2008;8(12):958-69.

39. Novak ML, Koh TJ. Phenotypic transitions of macrophages orchestrate tissue repair. Am J Pathol. 2013;183(5):1352-63. 
40. Shechter R, Schwartz M. CNS sterile injury: just another wound healing? Trends Mol Med. 2013;19(3):135-43.

41. Burda JE, Sofroniew MV. Reactive gliosis and the multicellular response to CNS damage and disease. Neuron. 2014;81(2):229-48.

42. Zhang Z, Krebs CJ, Guth L. Experimental analysis of progressive necrosis after spinal cord trauma in the rat: etiological role of the inflammatory response. Exp Neurol. 1997;143(1):141-52.

43. Friedlander RM, Gagliardini V, Rotello RJ, Yuan J. Functional role of interleukin 1 beta (IL-1 beta) in IL-1 beta-converting enzyme-mediated apoptosis. J Exp Med. 1996;184(2):717-24.

44. Rosenberg GA. Matrix metalloproteinases in brain injury. J Neurotrauma. 1995;12(5):833-42.

45. Brodie C. Differential effects of Th1 and Th2 derived cytokines on NGF synthesis by mouse astrocytes. FEBS Lett. 1996;394(2):117-20.

46. Knoblach SM, Faden Al. Interleukin-10 improves outcome and alters proinflammatory cytokine expression after experimental traumatic brain injury. Exp Neurol. 1998;153(1):143-51.

47. Genovese T, Esposito E, Mazzon E, Di Paola R, Caminiti R, Bramanti P, et al. Absence of endogenous interleukin-10 enhances secondary inflammatory process after spinal cord compression injury in mice. J Neurochem. 2009; 108(6):1360-72.

48. Takami T, Oudega M, Bethea JR, Wood PM, Kleitman N, Bunge MB. Methylprednisolone and interleukin-10 reduce gray matter damage in the contused Fischer rat thoracic spinal cord but do not improve functional outcome. J Neurotrauma. 2002;19(5):653-66.

49. Grillner S, Wallen P. Central pattern generators for locomotion, with special reference to vertebrates. Annu Rev Neurosci. 1985;8:233-61.

50. Whishaw IQ, Gorny B, Sarna J. Paw and limb use in skilled and spontaneous reaching after pyramidal tract, red nucleus and combined lesions in the rat: behavioral and anatomical dissociations. Behav Brain Res. 1998:93(1-2):16783.

51. Matsuyama K, Mori F, Nakajima K, Drew T, Aoki M, Mori S. Locomotor role of the corticoreticular-reticulospinal-spinal interneuronal system. Prog Brain Res. 2004;143:239-49.

52. Grillner S, Wallen P, Saitoh K, Kozlov A, Robertson B. Neural bases of goal-directed locomotion in vertebrates-an overview. Brain Res Rev. 2008;57(1):2-12.

53. McCrea DA, Rybak IA. Organization of mammalian locomotor rhythm and pattern generation. Brain Res Rev. 2008;57(1):134-46.

54. Williams PT, Kim S, Martin JH. Postnatal maturation of the red nucleus motor map depends on rubrospinal connections with forelimb motor pools. J Neurosci. 2014;34(12):4432-41.

55. Lawrence DG, Kuypers HG. The functional organization of the motor system in the monkey. I. the effects of bilateral pyramidal lesions. Brain. 1968;91(1):1-14.

56. Alstermark B, Lundberg A, Pettersson LG, Tantisira B, Walkowska M. Motor recovery after serial spinal cord lesions of defined descending pathways in cats. Neurosci Res. 1987;5(1):68-73.

57. Kennedy PR. Corticospinal, rubrospinal and rubro-olivary projections: a unifying hypothesis. Trends Neurosci. 1990;13(12):474-9.

58. Belhaj-Saif A, Cheney PD. Plasticity in the distribution of the red nucleus output to forearm muscles after unilateral lesions of the pyramidal tract. J Neurophysiol. 2000;83(5):3147-53.

59. Siegel CS, Fink KL, Strittmatter SM, Cafferty WB. Plasticity of intact rubral projections mediates spontaneous recovery of function after corticospinal tract injury. J Neurosci. 2015;35(4):1443-57.

60. Cramer GD, Darby SA, Cramer GD. Clinical anatomy of the spine, spinal cord, and ANS. 3rd ed. St. Louis: Elsevier; 2014. p. xv, 672.

61. Nathan PW, Smith MC. The rubrospinal and central tegmental tracts in man. Brain. 1982;105(Pt 2):223-69.

62. Fouad K, Pedersen V, Schwab ME, Brosamle C. Cervical sprouting of corticospinal fibers after thoracic spinal cord injury accompanies shifts in evoked motor responses. Curr Biol. 2001:11(22):1766-70.

63. Weidner N, Ner A, Salimi N, Tuszynski MH. Spontaneous corticospinal axonal plasticity and functional recovery after adult central nervous system injury. Proc Natl Acad Sci U S A. 2001;98(6):3513-8.

64. Bareyre FM, Kerschensteiner M, Raineteau O, Mettenleiter TC, Weinmann O, Schwab ME. The injured spinal cord spontaneously forms a new intraspinal circuit in adult rats. Nat Neurosci. 2004;7(3):269-77.

65. Filli L, Engmann AK, Zorner B, Weinmann O, Moraitis T, Gullo M, et al. Bridging the gap: a reticulo-propriospinal detour bypassing an incomplete spinal cord injury. J Neurosci. 2014;34(40):13399-410.

\section{Ready to submit your research? Choose BMC and benefit from:}

- fast, convenient online submission

- thorough peer review by experienced researchers in your field

- rapid publication on acceptance

- support for research data, including large and complex data types

- gold Open Access which fosters wider collaboration and increased citations

- maximum visibility for your research: over $100 \mathrm{M}$ website views per year

At BMC, research is always in progress.

Learn more biomedcentral.com/submissions 